\title{
Modeling and Simulation of Flexible Transmission Mechanism with Multiclearance Joints for Ultrahigh Voltage Circuit Breakers
}

\author{
Fangang Meng, Shijing Wu, Fan Zhang, Zenglei Zhang, Jicai Hu, and Xiaoyong Li \\ School of Power and Mechanical Engineering, Wuhan University, Wuhan 430072, China \\ Correspondence should be addressed to Shijing Wu; 76811886@qq.com
}

Received 20 April 2015; Accepted 3 August 2015

Academic Editor: Salvatore Strano

Copyright @ 2015 Fangang Meng et al. This is an open access article distributed under the Creative Commons Attribution License, which permits unrestricted use, distribution, and reproduction in any medium, provided the original work is properly cited.

The transmission mechanism, of which the dynamic characteristics determine the reliability of the circuit breaker, is the principal component of the ultrahigh voltage (UHV) circuit breaker. The characteristics of transmission mechanism are quick motion, high sensibility, and high reliability. The transmission mechanism with multiclearance joints present strong no-linear vibration feature which strongly affects the reliability of the UHV circuit breaker. In this investigation, a planar rigid-flexible coupling model of the transmission mechanism considering the clearance joints and the flexibility of components is established by using ADAMS software. The dynamic contact model in clearance joints is performed, based on clearance vector model of clearance joint. Then, the reliability of the model is proved by means of comparing the results of experiments. The simulation results show that the dynamic response of the mechanism is greatly influenced by the clearance and the flexibility of components has a role of suspension for the mechanism. Moreover, the influence of the clearance size, input speed, and number of clearance joints on the dynamic characteristics of the mechanism are also investigated.

\section{Introduction}

The ultrahigh voltage (UHV) circuit breaker is a device for protecting and controlling UHV transmission and distribution network. The main function of the UHV circuit breaker is that, when the signal of opening or closing is received, it disconnects or connects circuit with accuracy, efficiency, and stability in order to control and protect the grid. The transmission mechanism, of which the dynamic characteristics determine the reliability of the circuit breaker, is the principal component of the UHV circuit breaker. Compared with the driving mechanism of a low voltage circuit breaker, the transmission mechanism has a more complicated process, suffers heavier loads, and has a higher speed of moving contact. According to statistics, the mechanical failure of transmission mechanism accounted for $63.8 \%$ of all high voltage circuit breaker failures [1]. Therefore, the operation stability and reliability of UHV circuit breaker are directly determined by the performances of the transmission mechanism.
Lots of research works have been done on the circuit breaker by many domestic and foreign scholars, mainly focusing on the broken arc, the power source (hydraulic system and spring system), and the simulation research of the control circuit [2-6], while little attention had been paid to the dynamic characteristics of the transmission mechanism. The components of the transmission mechanism are mostly connected by hinges, while the clearance of the articulated kinematic pair is inevitable due to the assembling, manufacturing error and wear, and so forth [7-9]. The impact and collision caused by the clearance can result in vibration and noise of the mechanism, exacerbating mechanism wear and reducing mechanism kinematic accuracy, efficiency, and service life especially for high speed heavy haul mechanism [10].

Dynamic characteristic of mechanism is becoming one key concern of domestic and abroad mechanical engineering $[11,12]$. Over the last few decades, there are many scholars who have done a great deal of researches on the dynamic analysis of slider-crank or four-bar mechanisms with imperfect 
joints by using theoretical and experimental approaches. Flores et al. studied the influence of different contact force laws in the revolute joint with clearance on the dynamic responses of mechanism $[12,13]$. Khemili and Romdhane were interested in the study of the dynamic behavior of a planar flexible slider-crank mechanism with clearance; simulation and experimental tests were carried out for this goal [14]. The simulation and experimental result show that, in the presence of clearance, the coupler flexibility has role of suspension for the mechanism. Muvengei et al. numerically investigated the parametric effects of differently located frictionless revolute clearance joints on the overall dynamic characteristics of a typical slider-crank mechanism [15]. The simulation results reveal that the dynamic behavior of one clearance revolute joint cannot be used as a general case for a mechanical system. Megahed and Haroun established a model for a slider-crank mechanism considering multiple clearance joints, which was incorporated into ADAMS for conducting the dynamic simulation [16]. Bauchau and Rodriguez investigated the dynamic characteristics of clearance and flexibility on the dynamic response of the mechanism by establishing the dynamic equations based on the nonlinear dynamic theory [17]. Tian et al. studied the elasticity of the connecting links in mechanisms with clearance using all absolute nodal coordinate formulation based on Lankarani and Nikravesh's continuous force law and Coulomb's friction law $[18,19]$.

In most of previous works, the research object was only a simple slider-crank mechanism or four-bar mechanism. Also, the dynamic model of a mechanism with clearance has always considered one revolute clearance joint and neglected the flexibility of components, because considering more than one clearance joint and the flexibility of mechanism will make the dynamic analysis more complex. In this work, a planar rigid-flexible coupling dynamic model of high speed multilink transmission mechanisms with clearance for ultrahigh voltage circuit breaker $(1100 \mathrm{kv})$ is proposed using ADAMS software, based on the nonlinear continuous contact theory and the modified Coulomb friction model. Moreover, the elastic behavior of the collided bodies also is considered.

After an introduction, this paper is organized as follows. The physical structure and principle of the transmission mechanism with multiclearance joint for UHV are described briefly in Section 2. A contact force model based on clearance vector model of clearance joint is established in Section 3. The dynamic model of the transmission mechanism with multiclearance joint is established, and the reliability of the model under ADAMS is validated by experimental test in Section 4. Numerical simulations of the dynamic model are described and detailed discussion of the obtained results is presented in Section 5. Finally, the rigid-flexible model for the transmission mechanism of UHV is summarized and the conclusions are also outlined in Section 6.

\section{Description of the Transmission Mechanism}

As shown in Figure 1, the transmission mechanism of the UHV circuit breaker which completes on/off action is a multilink combination mechanism used to transmit force and motion. Driving link 1 is directly used to input the driving
TABLE 1: Parameters of the components in the mechanism.

\begin{tabular}{lccc}
\hline Body & $\begin{array}{c}\text { Length } \\
L_{i}(\mathrm{~m})\end{array}$ & $\begin{array}{c}\text { Mass } \\
M_{i}(\mathrm{~kg})\end{array}$ & $\begin{array}{c}\text { Moment of inertia } \\
I_{i}\left(\mathrm{~kg} \cdot \mathrm{m}^{2}\right)\end{array}$ \\
\hline 1 & 0.250 & 3.670 & 0.044 \\
2 & 0.248 & 3.720 & 0.015 \\
3 & 0.230 & 56.92 & 0.200 \\
4 & 0.210 & 4.760 & 0.010 \\
5 & 0.492 & 12.06 & 0.090 \\
6 & 0.900 & 81.54 & 0.051 \\
7 & 0.480 & 25.66 & 0.120 \\
8 & 0.280 & 13.25 & 0.027 \\
9 & 0.714 & 5.420 & 0.038 \\
\hline
\end{tabular}

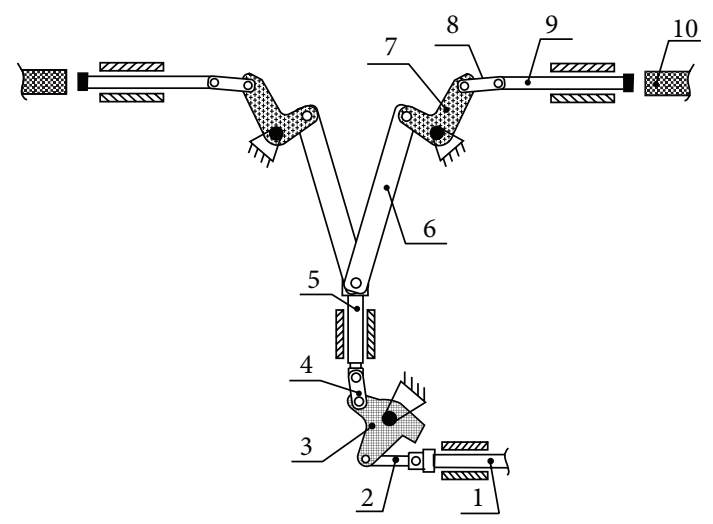

FIGURE 1: Transmission mechanism of the ultrahigh voltage circuit breaker. 1: driving link, 2: lower linkage, 3: lower turn arm, 4: lower linking board, 5: seal pole, 6: insulating pole, 7: upper turn arm, 8: upper linking board, 9: moving contact, and 10: static contact.

force. Insulation pole 6 is used to cut off the current. The transmission components between insulation pole 6 and moving contact 9 are located in the arc quenching chamber of the UHV circuit breaker. The horizontal stroke (input displacement) of driving link 1 is $230 \mathrm{~mm}$ while the horizontal stroke (output displacement) of the moving contact is $280 \mathrm{~mm}$. The closing time is $85 \mathrm{~ms}$ and the opening time is $40 \mathrm{~ms}$ during the opening and closing process of the UHV circuit breaker; thus the velocity of the transmission mechanism is so high that the instantaneous velocity can even reach up to $20 \mathrm{~m} / \mathrm{s}$. The components of the transmission mechanism above seal pole 5 have some symmetry. The right side of the mechanism is a 9-linkage planar mechanism with one degree of freedom that has three shifting pairs and ten revolute pairs. The characteristics parameters of each component of the mechanism are listed in Table 1 and the schematic diagram of the transmission mechanism with multiclearance joints is shown as in Figure 2.

\section{Contact Force Model of Clearance Joint}

3.1. Definition of Clearance Joints. It is assumed that the positional tolerance of the revolute joint is neglected. A revolute joint with clearance is shown in Figure 3. The difference in 


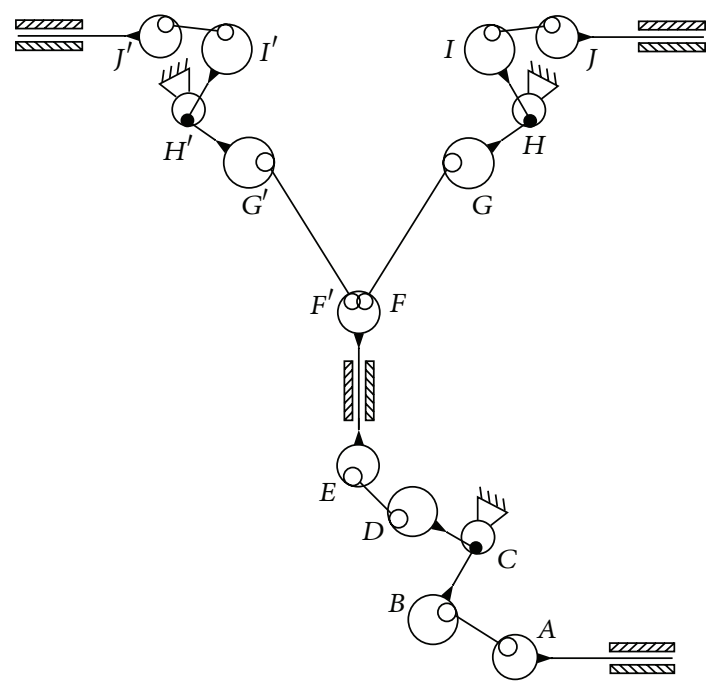

FIGURE 2: Schematic diagram of the transmission mechanism with multiclearance joints.

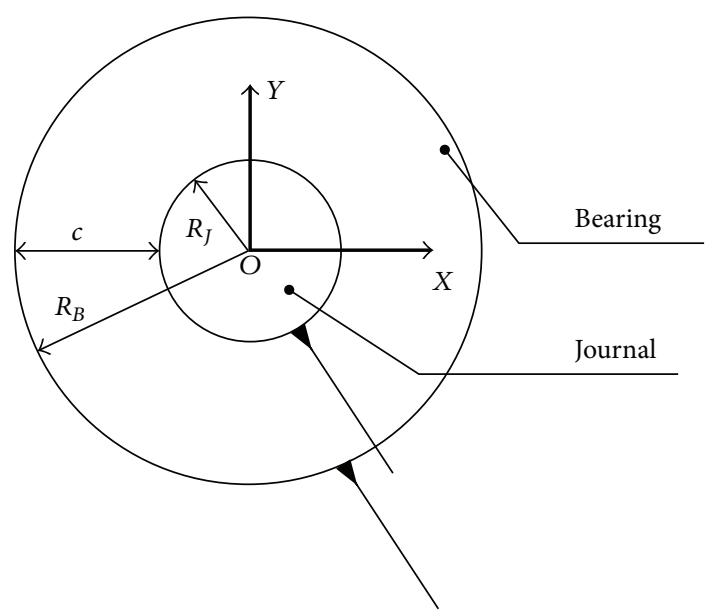

FIGURE 3: Schematic diagram of revolute joint with clearance.

radius between the bearing and the journal represents the size of the radial clearance.

Although a revolute joint with clearance does not constrain any degree of freedom from the mechanism, it introduces some kinematic constraints. This limits the journal to move within the bearing boundaries. Therefore, two kinematic constraints are removed and two extra degrees of freedom are introduced instead in a revolute clearance joint.

The difference in radius between the bearing and the journal is as follows:

$$
c=R_{B}-R_{J}
$$

where $R_{B}$ and $R_{J}$ represent the radius of bearing and journal.

Figure 4 depicts the three different types of motion between the bearing and journal during dynamics of the realistic revolute joint with clearance: (a) free flight mode, in which the journal and bearing are not in contact and the journal moves freely within the bearing boundaries, (b) impact mode, which presents at the end of the free flight mode, and (c) continuous contact mode; that is, contact is always maintained, despite the relative penetration depth between the bearing and journal.

Where $O_{i}$ and $O_{j}$ are the centers of bearing and journal, $\mathbf{r}_{\mathbf{i}}$ and $\mathbf{r}_{\mathbf{j}}$ represent the position vectors of bearing and journal in the global inertia coordinate. Thus, clearance vector can be given by

$$
\mathbf{e}_{\mathbf{i j}}=\mathbf{r}_{\mathbf{i}}-\mathbf{r}_{\mathbf{j}}
$$

where $\mathbf{e}_{\mathbf{i j}}$ represents the eccentric vector of journal relative to bearing. So the eccentricity of bearing and journal can be described as

$$
e_{i j}=\sqrt{e_{x}^{2}+e_{y}^{2}}
$$

The unit normal vector at the contact point of the bearing and journal is represented as

$$
\mathbf{n}=\frac{\mathbf{e}_{\mathbf{i j}}}{e_{i j}} .
$$

Figure 4(c) describes the relative penetration depth between the bearing and journal, which are represented in global coordinate system. The penetration depth caused by collision between bearing and journal can be stated as follows:

$$
\delta=e_{i j}-c
$$

3.2. Normal Force Model of Clearance Joint. For the modeling of the contact, the contact method based on the INPACT function is used to model. In this method, the contact force from the INPACT function is calculated by the ADAMS function library. The contact force is essentially modeled as a nonlinear spring-damper. From the simulations, ADAMS/Solver can give a continuous flow of responses, including accelerations, velocities, positions, and forces from all the elements and points of contact. This continuous contact force model is widely used for contact-impact process of mechanism system with joint clearance $[10,14]$.

It is clear that the normal contact model in ADAMS can be expressed as

$$
F_{n}= \begin{cases}0 & \delta \leq 0 \\ K \delta^{n}+D \dot{\delta} & \delta>0\end{cases}
$$

where $K \delta^{n}$ represents the elastic deformation force, $D(\delta) \dot{\delta}$ represents the energy dissipation, $\delta$ is the penetration depth, and $\dot{\delta}$ is the relative impact velocity. The exponent of the force deformation characteristic, $n$, depends on the material of the contact surfaces ( $n$ is set to 1.5 for metallic material) [20]. $D(\delta)$ 


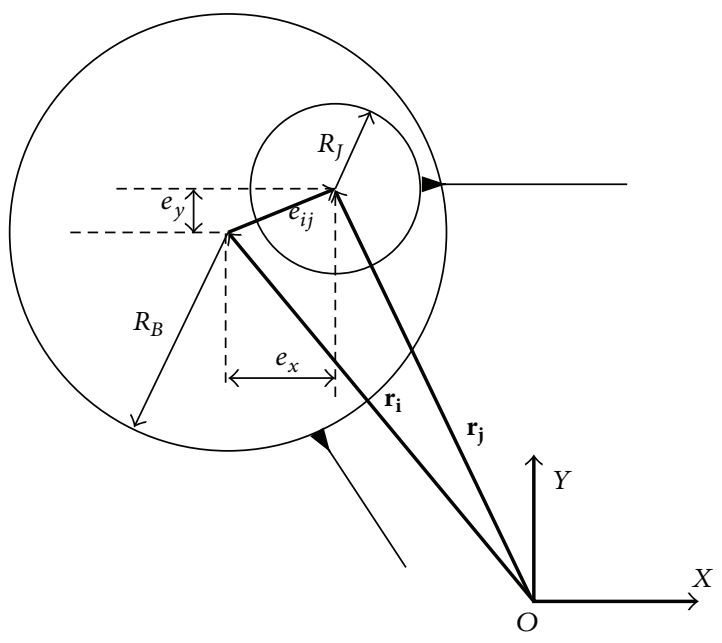

(a) Free light mode

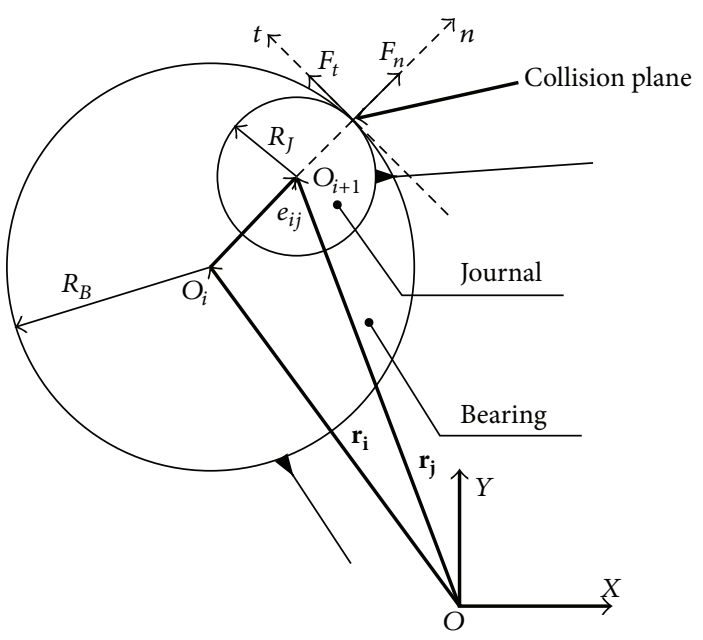

(b) Impact mode

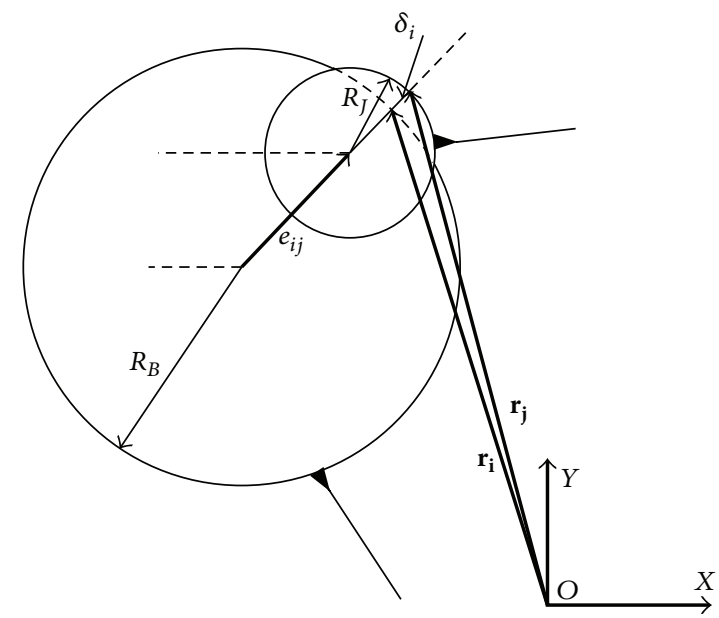

(c) Contact mode

FIgURE 4: Realistic revolute joint with clearance.

is the instantaneous damping coefficient, which can be given by

$$
\begin{aligned}
& D(\delta) \\
& \quad= \begin{cases}0 & \delta \leq 0 \\
D_{\max }\left(\frac{\delta}{d_{\max }}\right)^{2}\left(3-2 \frac{\delta}{d_{\max }}\right) & 0<\delta \leq d_{\max } \\
D_{\max } & \delta>d_{\max },\end{cases}
\end{aligned}
$$

where $D_{\max }$ is the maximum value of the damping coefficient, $d_{\max }$ is the maximum value of penetration depth, and $D(\delta)$ is a function with respect to $D_{\max }, \delta$, and $d_{\max }$, as shown in Figure 5. One has

$$
\begin{aligned}
H_{\mathrm{avg}} & =\frac{2 K\left(1-r^{2}\right)}{4 \delta^{\bullet-}}, \\
D_{\max } & =H_{\mathrm{avg}} d_{\max }^{n} .
\end{aligned}
$$

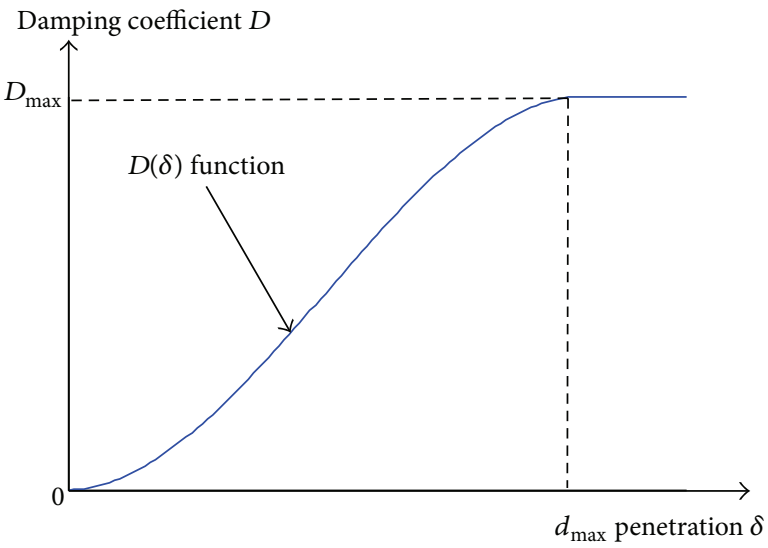

Figure 5: $D(\delta)$ function.

The maximum damping coefficient $D_{\max }$ is calculated using (8), and more accurate values of $D_{\max }$ can be obtained by updating the values of $D_{\max }$ and $\delta^{\circ-}$ using numerical iteration till the value of $D_{\max }$ is stabilized. 


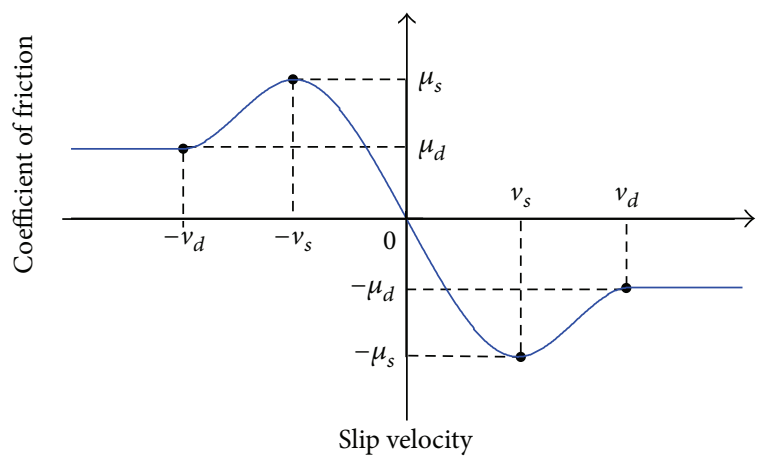

FIgURE 6: Coefficient of friction versus slip velocity.

The stiffness parameter $K$ can be calculated as follows:

$$
\begin{aligned}
K & =\frac{4}{3\left(\sigma_{1}+\sigma_{2}\right)}\left[\frac{R_{1} R_{2}}{R_{1}+R_{2}}\right]^{1 / 2}, \\
\sigma_{i} & =\frac{\left(1-v_{i}^{2}\right)}{E_{i}} \quad(i=1,2), \\
\frac{1}{E^{*}} & =\frac{\left(1-v_{1}^{2}\right)}{E_{1}}+\frac{\left(1-v_{2}^{2}\right)}{E_{2}},
\end{aligned}
$$

where $R_{1}$ and $R_{2}$ represent, respectively, the radii of bearing and journal, $v_{i}$ is Poisson's ratio, and $E_{i}$ is Yong's modulus for element $i$.
The expression of nonlinear continuous contact force model is expressed as follows:

$$
F_{n}= \begin{cases}0 & \delta \leq 0 \\ K \delta^{n}+D \dot{\delta} & \delta>0\end{cases}
$$

3.3. Friction Force Model of Clearance Joint. In this paper, the tangential contact force of clearance is calculated using the modified Coulomb friction model [21]. Friction coefficient of the modified Coulomb friction model is function of tangential sliding velocity, which can avoid the abrupt change of friction in the course of numerical calculating as the change of velocity direction. And, also, the modified Coulomb friction induces the viscous and microslip phenomenon in relative motion more accurately.

The tangential contact forces model can be represented by

$$
F_{t}=-\mu\left(v_{t}\right) F_{n} \frac{v_{t}}{\left|v_{t}\right|},
$$

where $v_{t}$ is sliding velocity in tangential direction at the collision point of journal and bearing, that is, the velocity component in tangential direction.

$\mu\left(v_{t}\right)$ is friction coefficient, which can be expressed as

$$
\mu\left(v_{t}\right)=\left\{\begin{array}{lr}
-\mu_{d} \operatorname{sign}\left(v_{t}\right) & \text { for }\left|v_{t}\right|>v_{d} \\
-\left\{\mu_{d}+\left(\mu_{s}-\mu_{d}\right)\left(\frac{\left|v_{t}\right|-v_{s}}{v_{d}-v_{s}}\right)^{2}\left[3-2\left(\frac{\left|v_{t}\right|-v_{s}}{v_{d}-v_{s}}\right)\right]\right\} \operatorname{sign}\left(v_{t}\right) & \text { for } v_{s}<\left|v_{t}\right|<v_{d} \\
-\mu_{s}-2 \mu_{s}\left(\frac{v_{t}+v_{s}}{2 v_{s}}\right)^{2}\left(3-\frac{v_{t}+v_{s}}{v_{s}}\right) & \text { for }\left|v_{t}\right|<v_{s},
\end{array}\right.
$$

where $v_{d}$ is maximum critical velocity of the kinetic friction, $v_{s}$ is critical velocity of static friction, $\mu_{d}$ is kinetic friction coefficient, and $\mu_{s}$ is static friction coefficient. The function curve of kinetic friction coefficient can be described as in Figure 6.

\section{Modeling of the Mechanism with Clearance and Experimental Verification}

4.1. Dynamic Model of Transmission Mechanism of UHV with Clearance. The high speed multilink transmission mechanism of UHV with multiclearance joint was established under ADAMS, as shown in Figure 7. During the dynamic simulation of ADAMS, it is assumed that the revolute joints with clearance are studied under the condition of dry lubrication, and no wear occurs at the joints. The insulating pole, upper turn arm, upper linking board, and $t$ moving contact are flexible, which are established under the finite element software HYPERMESH for obtaining their eigenfrequencies and eigenmodes (Figure 8). The material properties of the flexible components are presented in Table 2. Moreover, the first twelve modes with corresponding natural frequencies are chosen for the simulation of dynamics of the rigid-flexible coupling mechanism with clearance. The modal neutral files (.mnf) of flexible components are exported into the ADAMS to connect with other rigid components of the mechanism. The rigid-flexible coupling model of transmission mechanism with multiclearance joints under ADAMS can obtain more accurate dynamic responses of the mechanism.

In order to obtain the best numerical results, the Gear Stiff (GSTIFF) integrator is chosen, which uses a backwards differentiation formula (BDF) to integrate differential and algebraic standard index-three equations. It provides good solutions for simulations of stiff models (models with a mix of high and low frequencies) using modified Newton-Raphson 
The transmission mechanism of UHV with multiclearance joint modeled under ADAMS

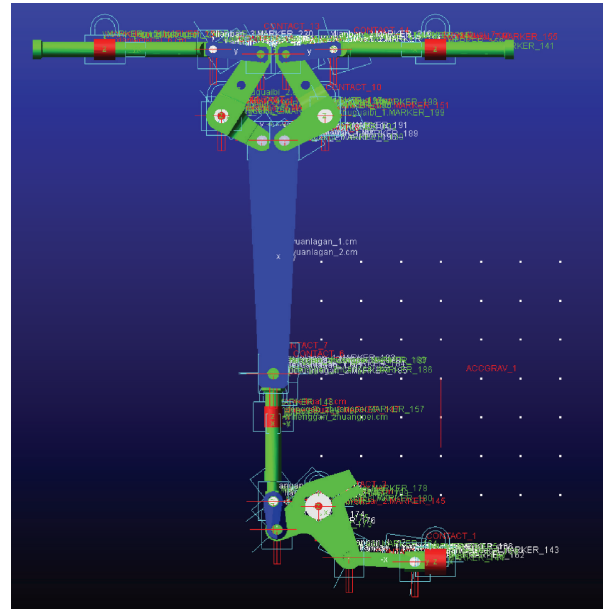

Closing position

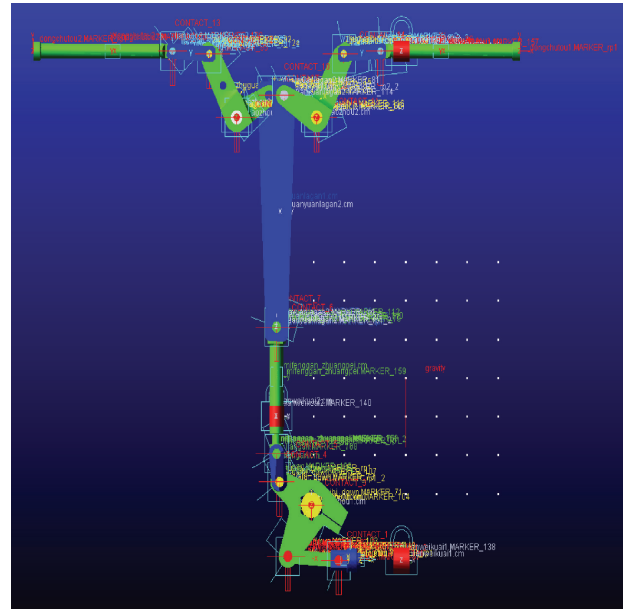

Opening position

FIgURE 7: Transmission mechanism modeled in ADAMS.

Upper turn arm

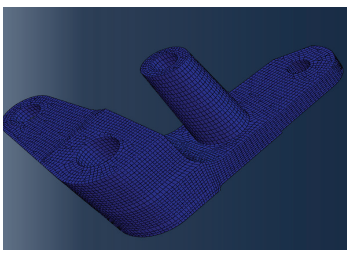

Undeformed flexible element

Natural frequency: $1055.7 \mathrm{~Hz}$

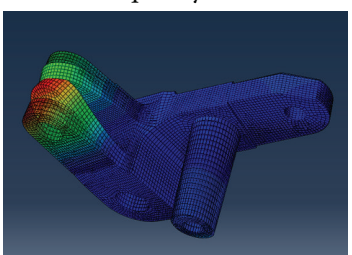

Second mode

Moving contact

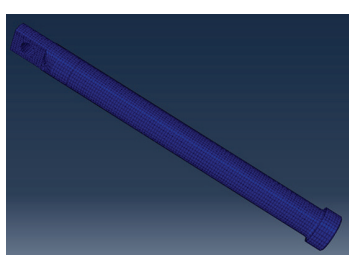

Undeformed flexible element

Natural frequency $: 1560.8 \mathrm{~Hz}$

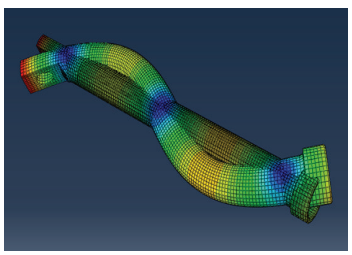

Second mode

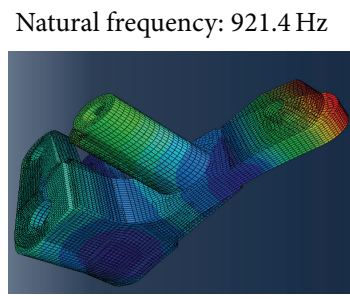

First mode

Natural frequency: $1309.5 \mathrm{~Hz}$

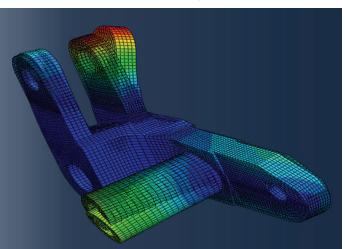

Third mode

Natural frequency: $564.5 \mathrm{~Hz}$

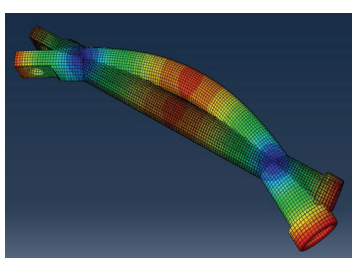

First mode

Natural frequency: $2748.6 \mathrm{~Hz}$

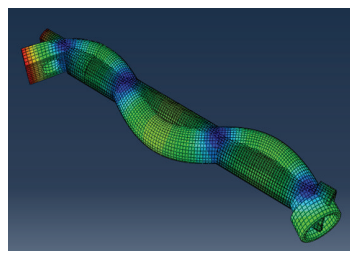

Third mode
Insulating pole

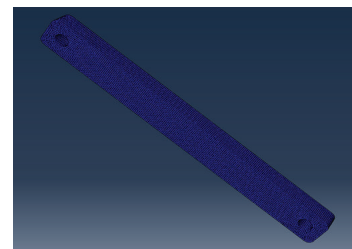

Undeformed flexible element

Natural frequency: $573.2 \mathrm{~Hz}$

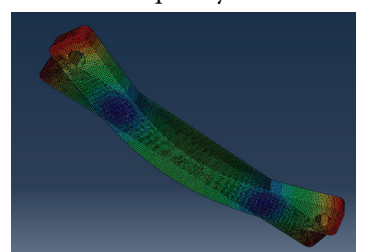

Second mode

Upper linking board

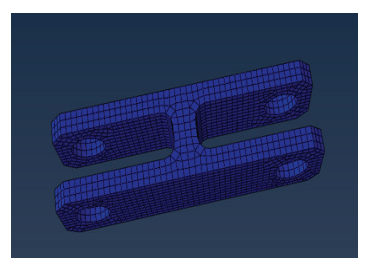

Undeformed flexible element

Natural frequency: $1194.8 \mathrm{~Hz}$

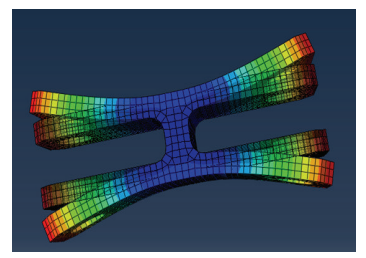

Second mode
Natural frequency: $266.1 \mathrm{~Hz}$

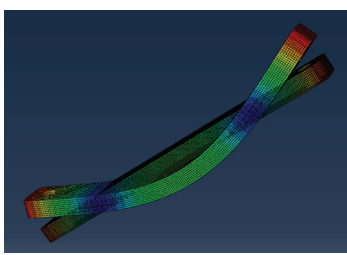

First mode

Natural frequency: $713.4 \mathrm{~Hz}$

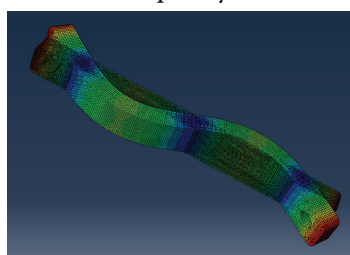

Third mode

Natural frequency: $971.8 \mathrm{~Hz}$

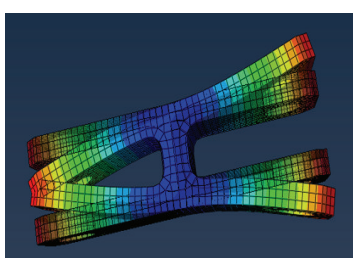

First mode

Natural frequency: $1607.4 \mathrm{~Hz}$

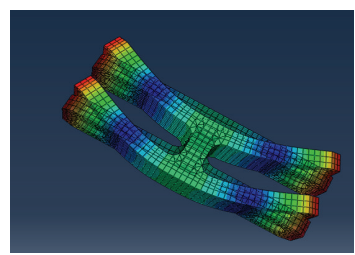

Third mode

FIGURE 8: Flexible coupler: eigenfrequencies and eigenmodes computation. 


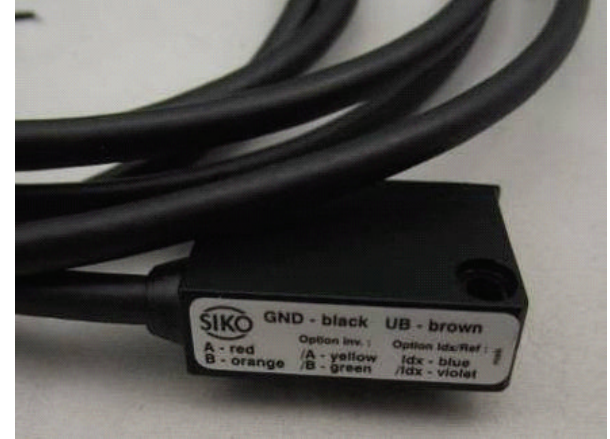

(a) Magnetic railings ruler

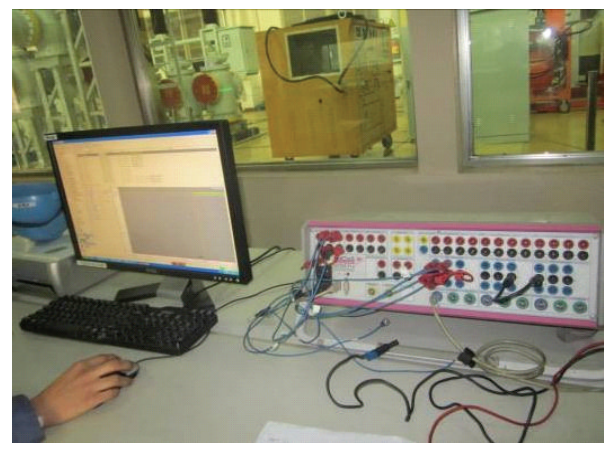

(c) ACTAS tester

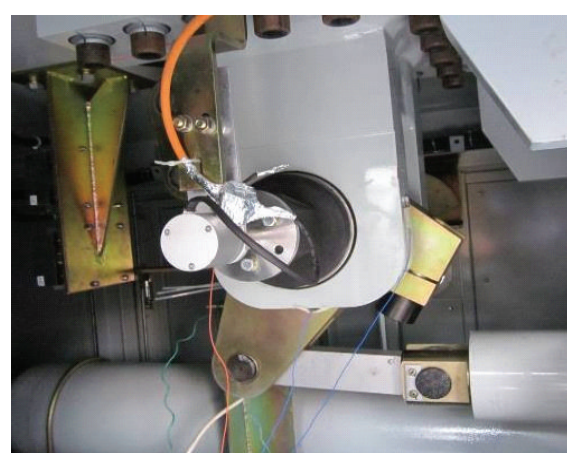

(b) The installation of sensor

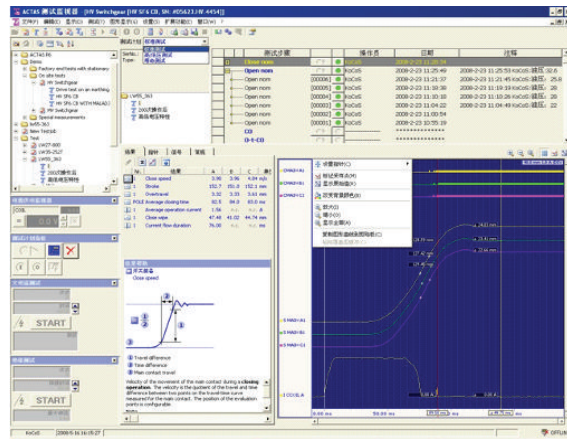

(d) Test interface

Figure 9: Experimental test system.

TABLE 2: The material properties of the flexible components.

\begin{tabular}{lccc}
\hline Flexible components & $\begin{array}{c}\text { Modulus of } \\
\text { elasticity (Pa) }\end{array}$ & $\begin{array}{c}\text { Poisson's } \\
\text { ration }\end{array}$ & $\begin{array}{c}\text { Density } \\
\left(\mathrm{kg} / \mathrm{m}^{3}\right)\end{array}$ \\
\hline Insulating pole & $1.03 \times 10^{12}$ & 0.3 & 7600 \\
Upper turn arm & $2.11 \times 10^{12}$ & 0.25 & 7850 \\
Upper linking board & $2.11 \times 10^{12}$ & 0.277 & 7850 \\
Moving contact & $2.13 \times 10^{12}$ & 0.286 & 7870
\end{tabular}

iterative algorithm in the numerical integrating of the difference equation [22]. The maximum number of the iterations allowed for the solution of the nonlinear equations using Newton-Raphson method to converge is ten. The integrator formulation (SI1) has been chosen for the selected integration method (GSTIFF) since it takes the constraint derivatives into account when solving the equations of motion and monitors the integration error on the impulse of the Lagrange Multipliers in the system. The contact model of Section 3 is incorporated into ADAMS, which is used to simulate the clearance joint. The simulation characteristics are listed in Table 3.

4.2. Experimental Verification. The experimental test system is shown in Figure 9. The displacement of seal pole is measured by using magnetic railings ruler, which can reduce the negative impact of mechanical vibration on the experimental test. The rotational angular velocity of lower turn arm is measured by using ROS Photoelectric RotatingSpeed Sensor, which can avoid the influence of extra load on
TABLE 3: Simulation characteristics.

\begin{tabular}{lc}
\hline Stiffness coefficients $K(\mathrm{~N} / \mathrm{m})$ & $3.81 \times 10^{7}$ \\
Force exponent $n$ & 1.5 \\
Damping coefficient $D(\mathrm{~N} \cdot \mathrm{s} / \mathrm{m})$ & $3.81 \times 10^{5}$ \\
Normal maximum penetration $\delta_{\max }(\mathrm{m})$ & $1.0 \times 10^{-5}$ \\
Static friction coefficient $\mu_{s}$ & 0.2 \\
Dynamic friction coefficient $\mu_{d}$ & 0.16 \\
Stiction translation velocity $v_{s}(\mathrm{~m} / \mathrm{s})$ & $1.0 \times 10^{-4}$ \\
Friction translation velocity $v_{d}(\mathrm{~m} / \mathrm{s})$ & $1.0 \times 10^{-2}$ \\
Radius of the solids in contact $R(\mathrm{~m})$ & 0.05 \\
Modulus of elasticity $E(\mathrm{~Pa})$ & $2.07 \times 10^{11}$ \\
Poisson's ratio $\mu$ & 0.3 \\
Density $\rho\left(\mathrm{kg} / \mathrm{m}^{3}\right)$ & $7.8 \times 10^{3}$ \\
Max. number of iteration & 100 \\
Initial time step & $1.0 \times 10^{-7}$ \\
Max. time step & $1.0 \times 10^{-3}$ \\
Min. time step & $1.0 \times 10^{-9}$ \\
Accuracy & $1.0 \times 10^{-7}$ \\
Jacobian pattern & $100 \%$ \\
\hline
\end{tabular}

the experimental test. Then German's ACTAS tester was used for treatment of experimental data, which can confirm high accuracy and reliability on the treatment of experimental data for its high accuracy and linear frequency responses under various complex electromagnetic environments.

Figure 11 shows a comparison between the experimental and the simulation results. During the dynamic simulation, 


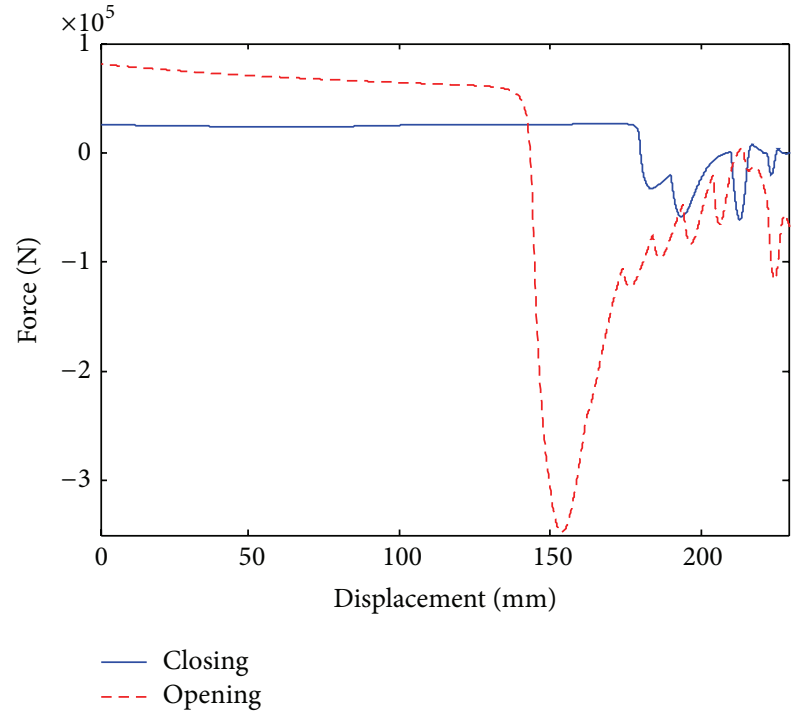

(a) Driving force of the driving link

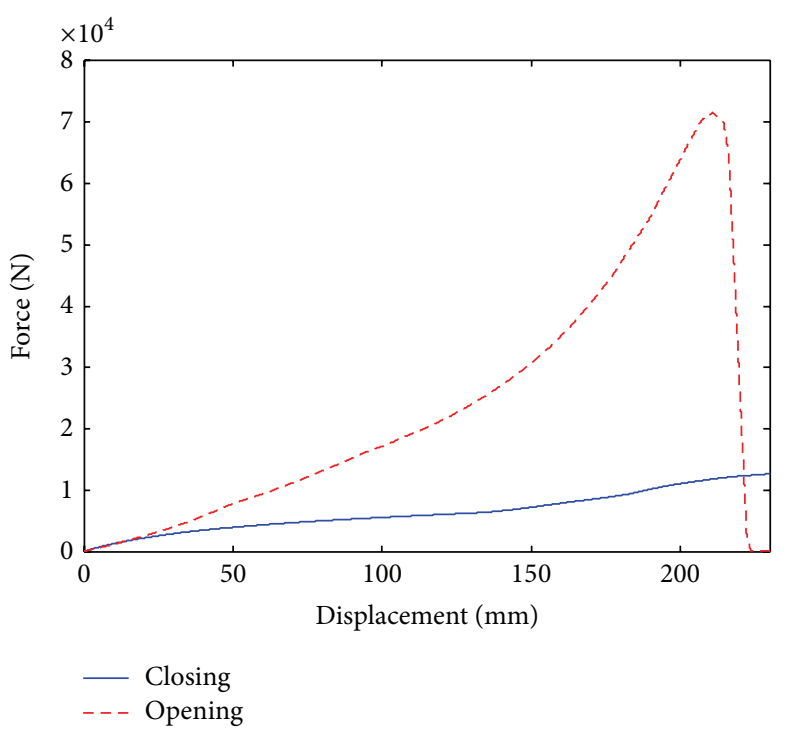

(b) Load force of the moving contact

FIgURE 10: Driving force and load force.

the driving force of the driving link and the load force of the moving contact can be expressed as in Figure 10. The revolute joints $A$ and $B$ (Figure 2) of the rigid-flexible coupling model were modeled as clearance joints and others are ideal revolute joints. The clearance size of the revolute joint is set to be $0.1 \mathrm{~mm}$ for the present work, which is supported by manufacturing error and assemblage. It is shown that the simulation and experimental results are in good agreement.

\section{Result and Discussion}

In order to study the dynamic characteristics of transmission mechanism with multiclearance joints, the STEP5 function in ADAMS is selected as input function of motion. The STEP5 function provides approximation to the Heaviside step function with a quintic polynomial, which can meet the requirements for input displacement and closing time of transmission mechanism.

The format defining the STEP5 function is

$$
\operatorname{STEP} 5\left(x, x_{0}, h_{0}, x_{1}, h_{1}\right),
$$

where $x$ is the independent variable, $x_{0}$ and $x_{1}$ are real variables that specify the $x$ value at which the STEP5 function begins and ends, respectively, and $h_{0}$ and $h_{1}$ are the initial and final value of the step.

The equation defining the STEP5 function is

$$
\begin{aligned}
& \alpha=h_{1}-h_{0}, \\
& \Delta=\frac{\left(x-x_{0}\right)}{\left(x_{1}-x_{0}\right)},
\end{aligned}
$$

\section{STEP5}

$$
= \begin{cases}h_{0} & x \leq x_{0} \\ h_{0}+\alpha \Delta^{3}\left[10-15 \Delta+6 \Delta^{2}\right] & x_{0}<x \leq x_{1} \\ h_{1} & x>x_{1} .\end{cases}
$$

During the dynamic simulation, the motion time of the mechanism is $0.085 \mathrm{~s}$ and the input stroke is $230 \mathrm{~mm}$; therefore, the input function STEP5 can be set as

$$
\text { STEP5 (time, 0, 0, 0.085, 230). }
$$

The input displacement of motion and corresponding input velocity can be described as in Figure 12.

5.1. Dynamic Responses Based on the Rigid Model of the Transmission Mechanism with Clearance. During the dynamic simulation, the revolute joints $A$ and $J$ (Figure 2) of the rigid-flexible coupling model are modeled as clearance joints and others are ideal revolute joints. The clearance size of the revolute joint is set to $0.1 \mathrm{~mm}$, while the simulation time duration is $0.085 \mathrm{~s}$. The displacement, velocity, and acceleration of the moving contact for rigid model are shown in Figure 13.

As can be observed from Figure 13, the effects of clearance on acceleration of transmission mechanism are severer than the effects of clearance on displacement and velocity. The displacement and velocity of the transmission mechanism with clearance are generally consistent with those without clearance. The deviation value of the output stroke of the moving contact is $0.1 \mathrm{~mm}$. The existence of clearance leads to oscillating and time delay of the velocity. Remarkably, the existence of clearance induces the high-frequency shake of 


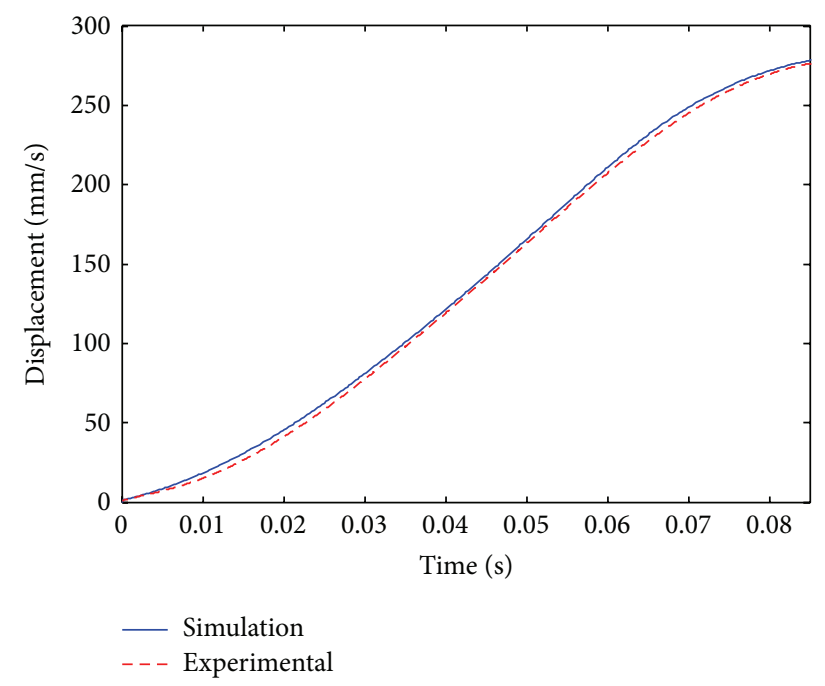

(a) Displacement of moving contact in the closing process

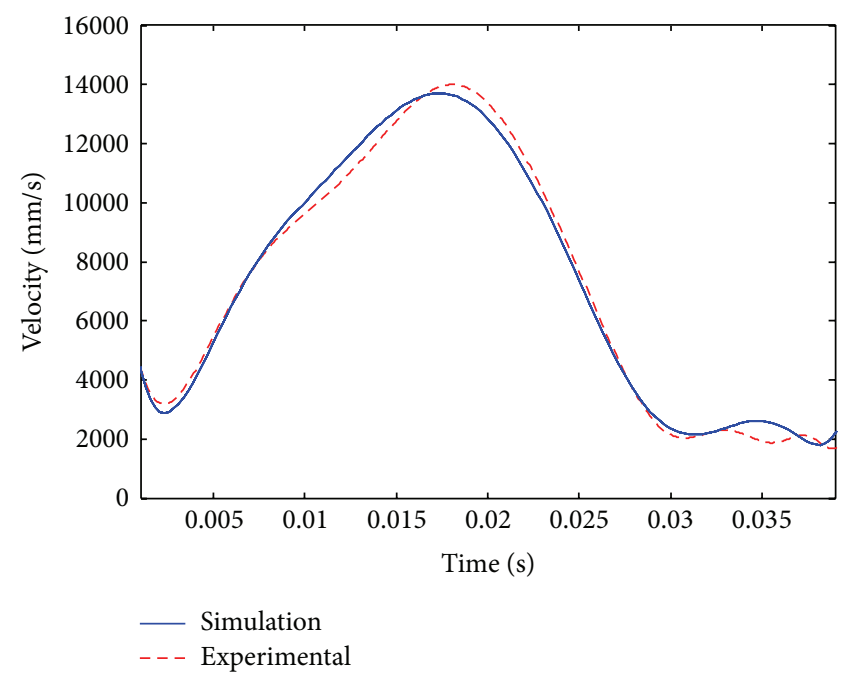

(c) Velocity of moving contact in the opening process

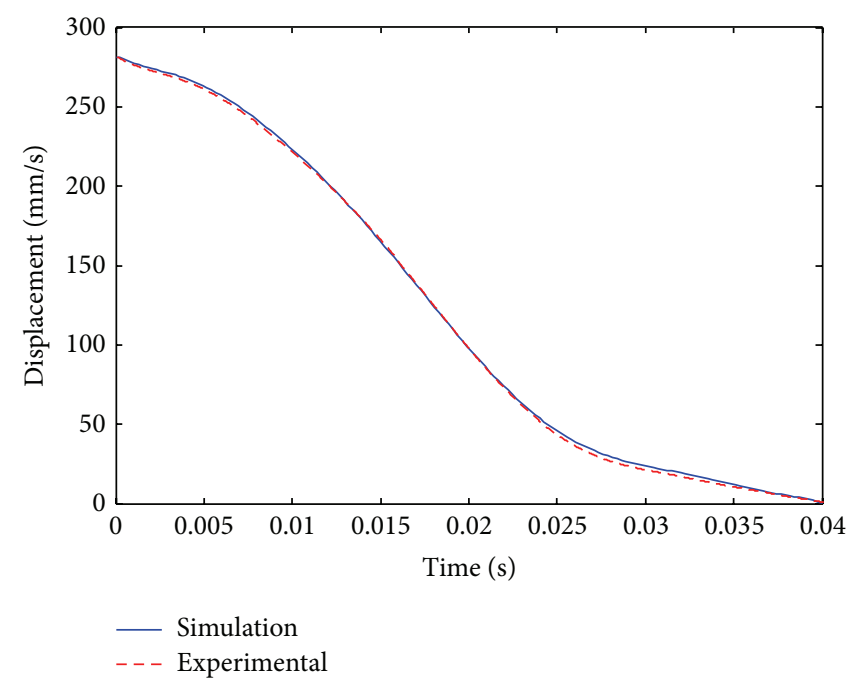

(b) Displacement of moving contact in the opening process

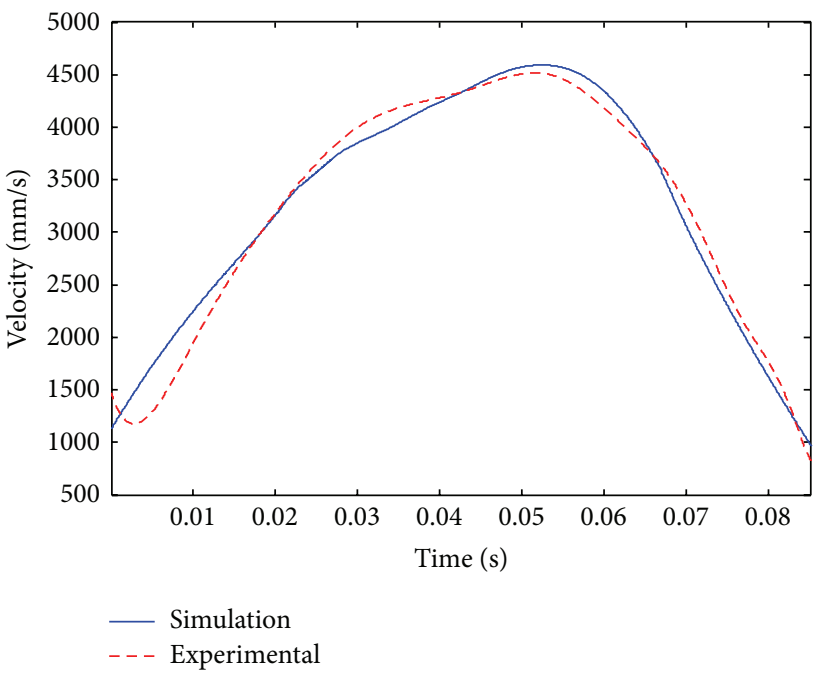

(d) Velocity of moving contact in the opening process

FIGURE 11: Simulation and experimental results.

acceleration, and the maximum value of acceleration of the mechanism is 2.29 times more than that of the mechanism without clearance. It is clear that the existence of the clearance joint has an important effect on the dynamic response of the mechanism, and the clearance joint must be considered for reliable analysis of the mechanisms.

\subsection{Dynamic Responses Based on the Rigid-Flexible Coupling} Model of Transmission Mechanism with Clearance. In order to highlight the effect of flexibility, the same simulation characteristics as in the case of the rigid transmission mechanism are chosen. The displacement, velocity, and acceleration of the moving contact for rigid-flexible coupling model are shown in Figure 14.

As can be seen from Figure 14, the displacement and velocity of the transmission mechanism with clearance are

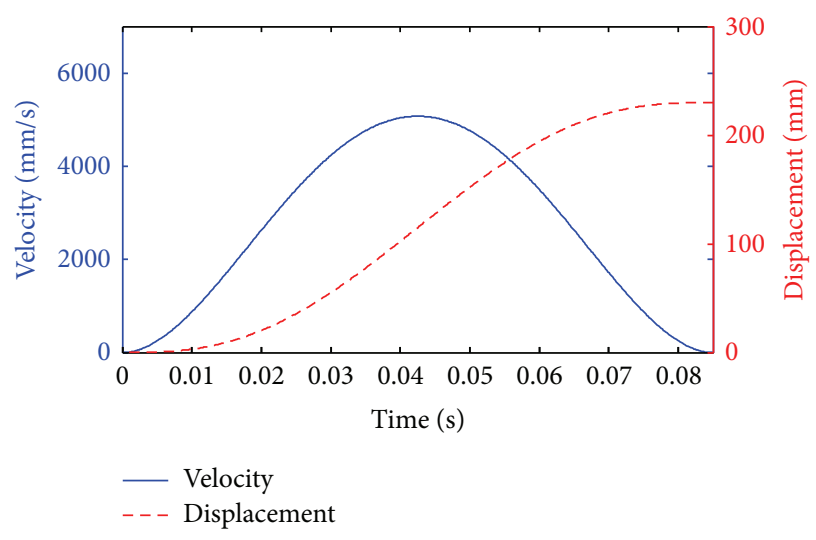

FIGURE 12: Characteristics of the input displacement and velocity (STEP5). 


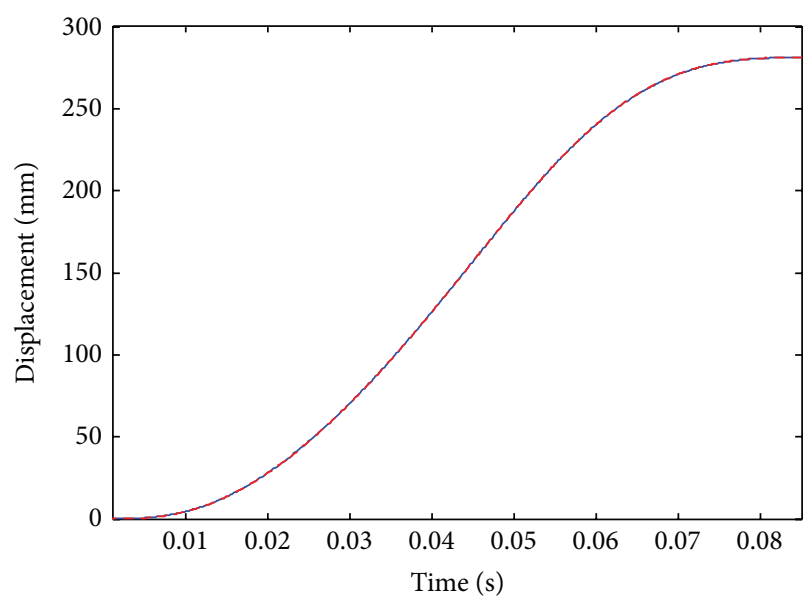

- Without clearance - . - With clearance

(a)

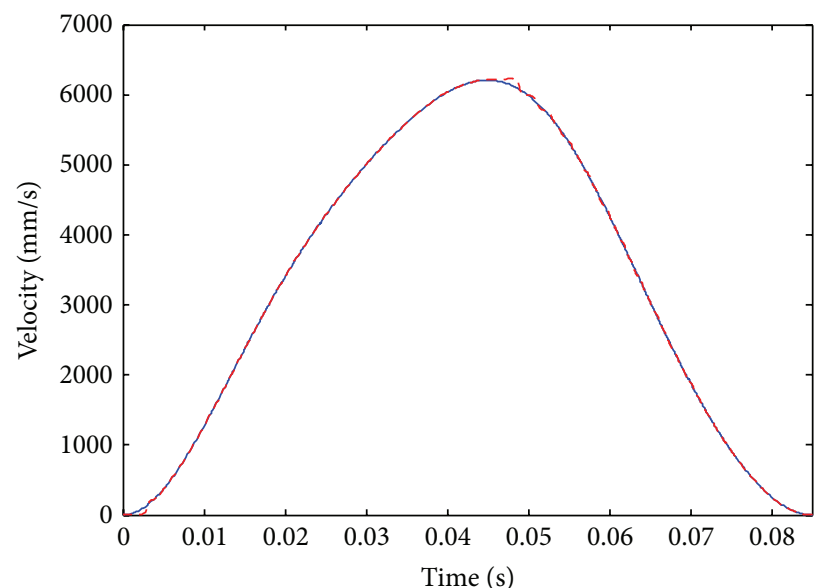

Without clearance - - - With clearance

(c)

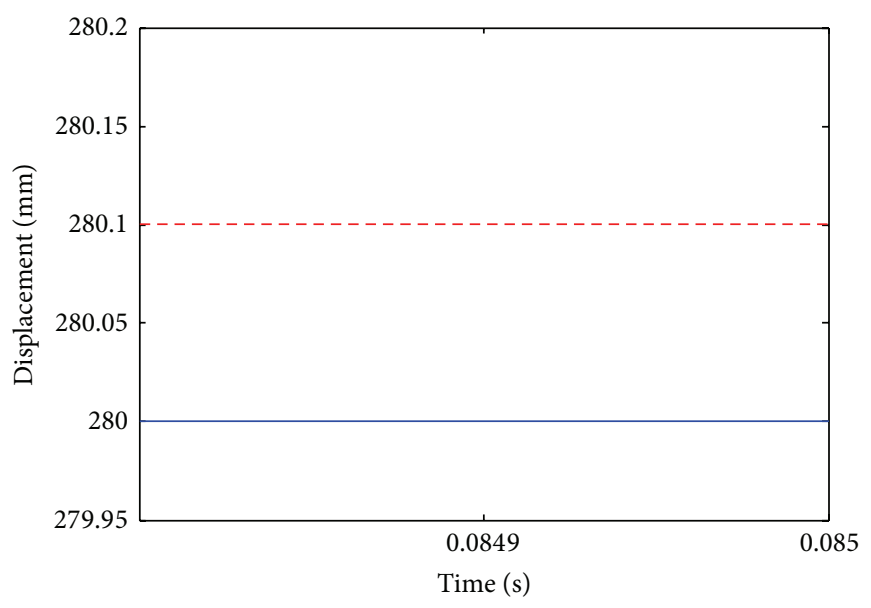

- Without clearance

- . - With clearance

(b)

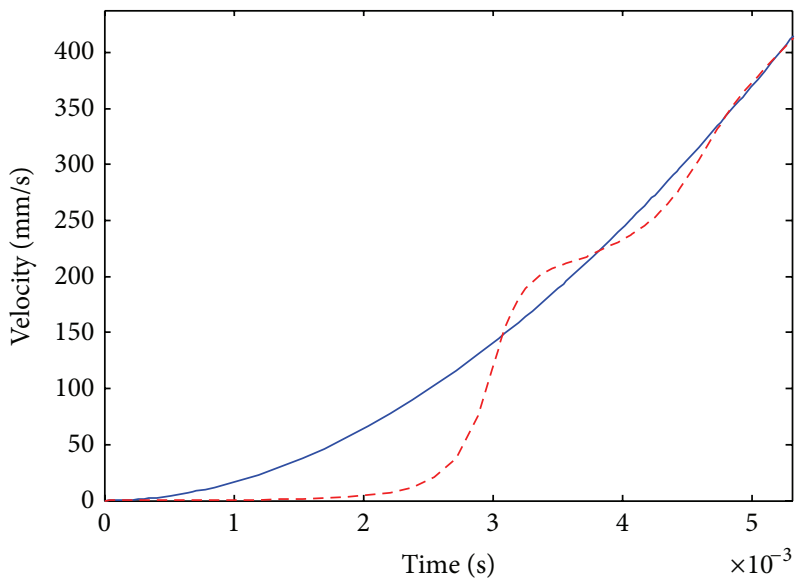

- Without clearance

- - - With clearance

(d)

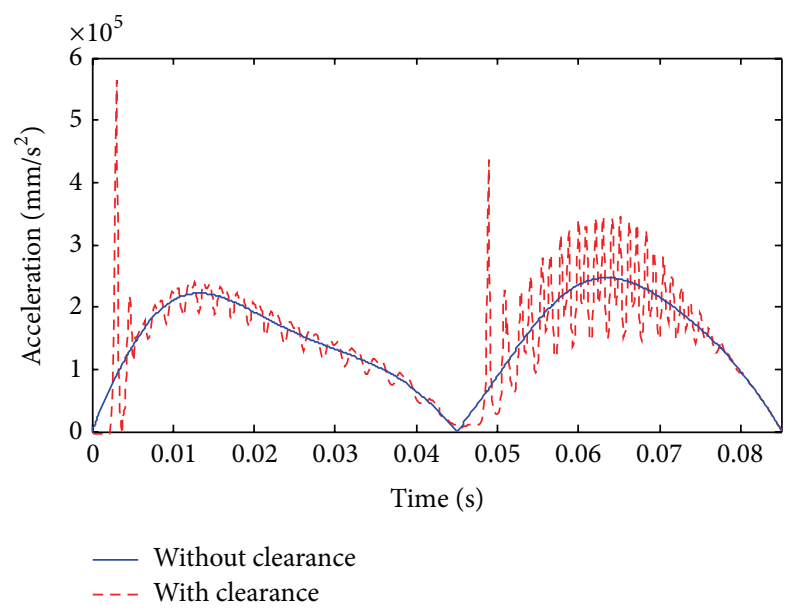

(e)

FIGURE 13: Responses based on the rigid model with clearance: (a) displacement, (b) enlarged drawing of displacement, (c) velocity, (d) enlarged drawing of velocity, and (e) acceleration. 


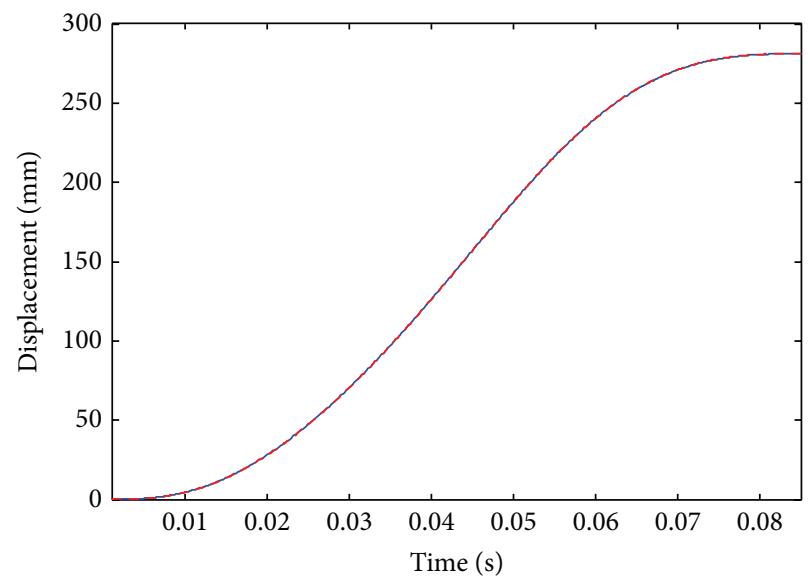

- Without clearance - . - With clearance

(a)

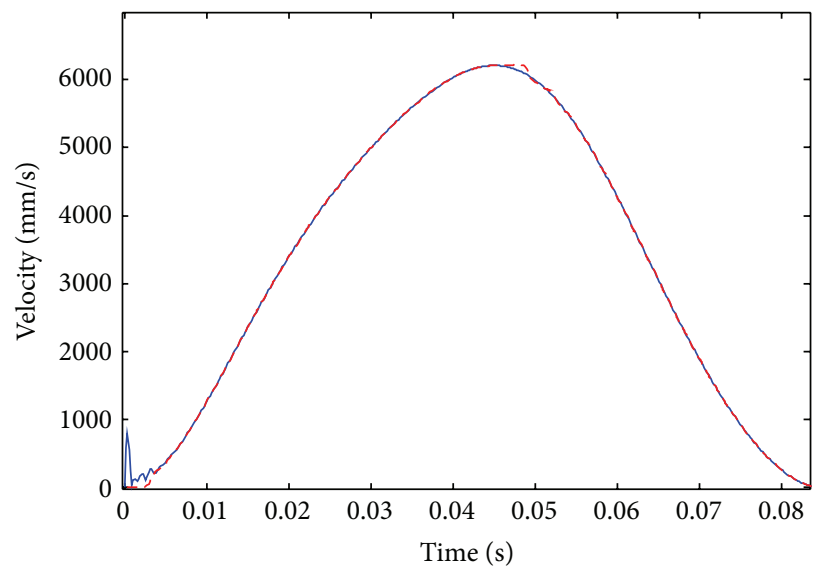

- Without clearance

- - - With clearance

(c)

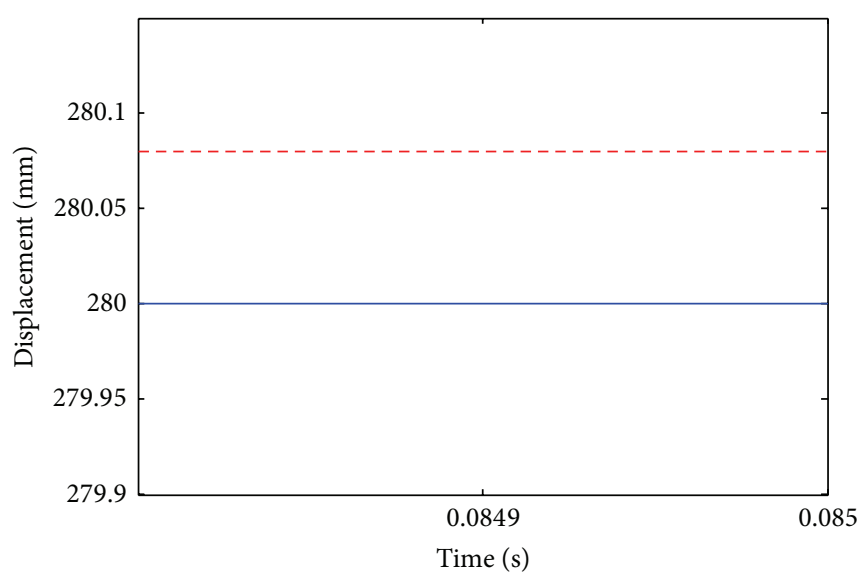

- Without clearance

- - - With clearance

(b)

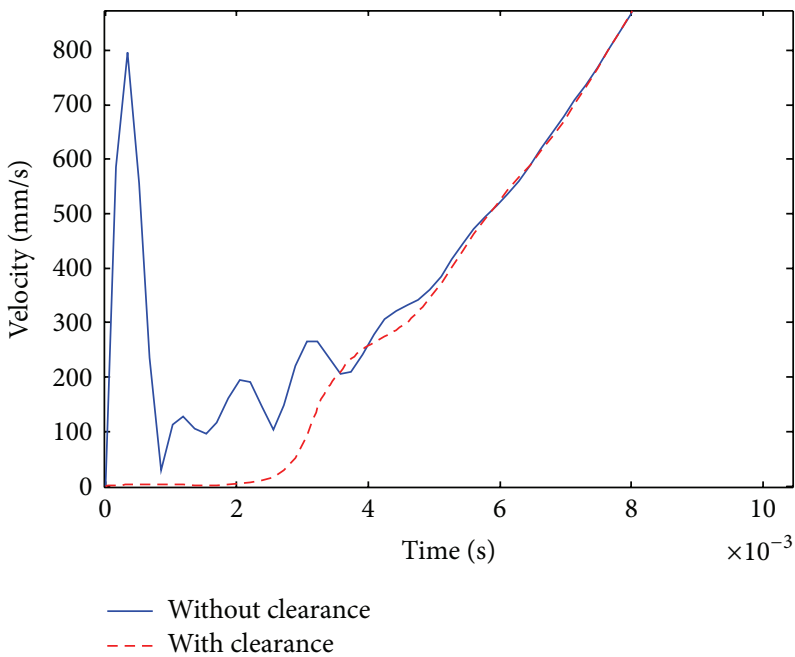

(d)

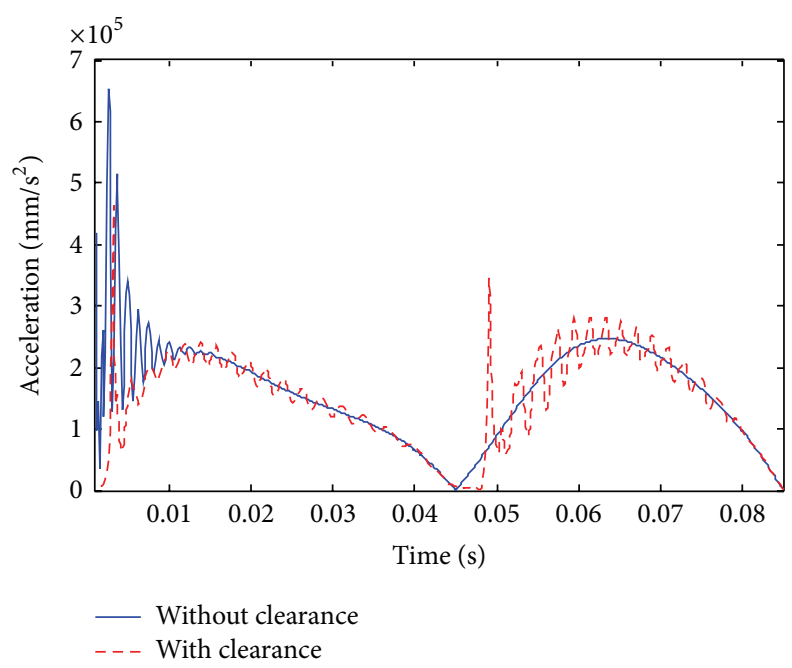

(e)

FIGURE 14: Responses based on the rigid-flexible coupling model with clearance: (a) displacement, (b) enlarged drawing of displacement, (c) velocity, (d) enlarged drawing of velocity, and (e) acceleration. 


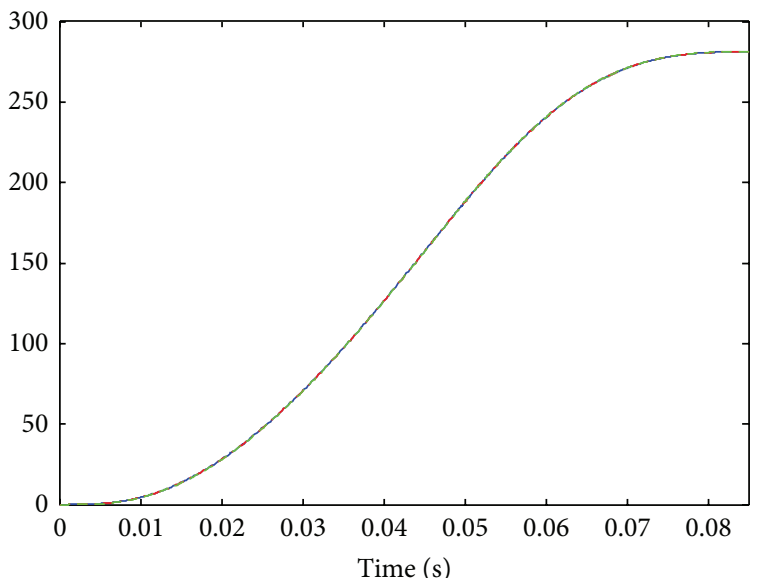

$\longrightarrow c=0.05 \mathrm{~mm}$

-. - $c=0.1 \mathrm{~mm}$

(a)

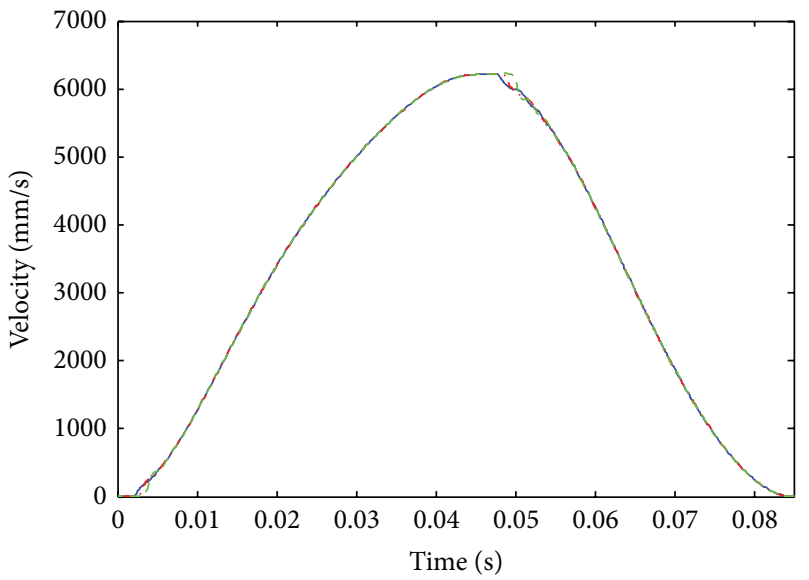

$\longrightarrow c=0.05 \mathrm{~mm}$

. -. $-c=0.1 \mathrm{~mm}$

(c)

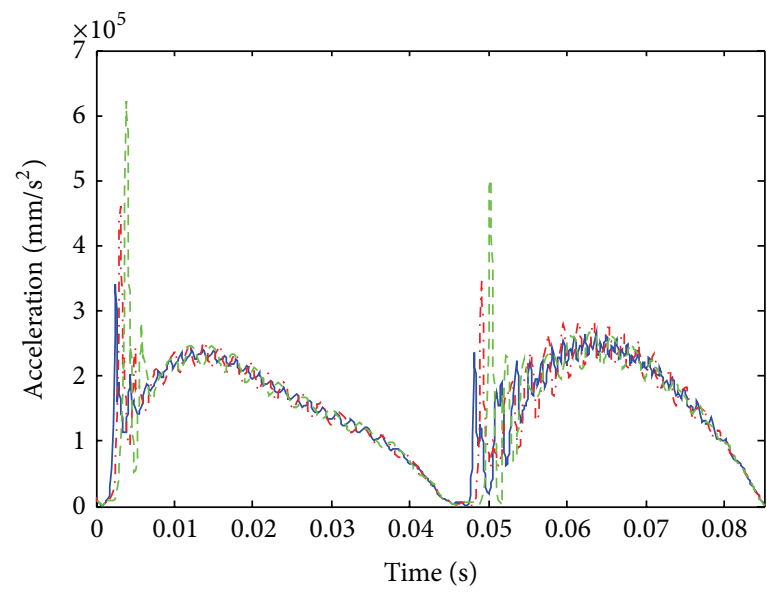

$-c=0.05 \mathrm{~mm}$

-. $c=0.1 \mathrm{~mm}$

(e)

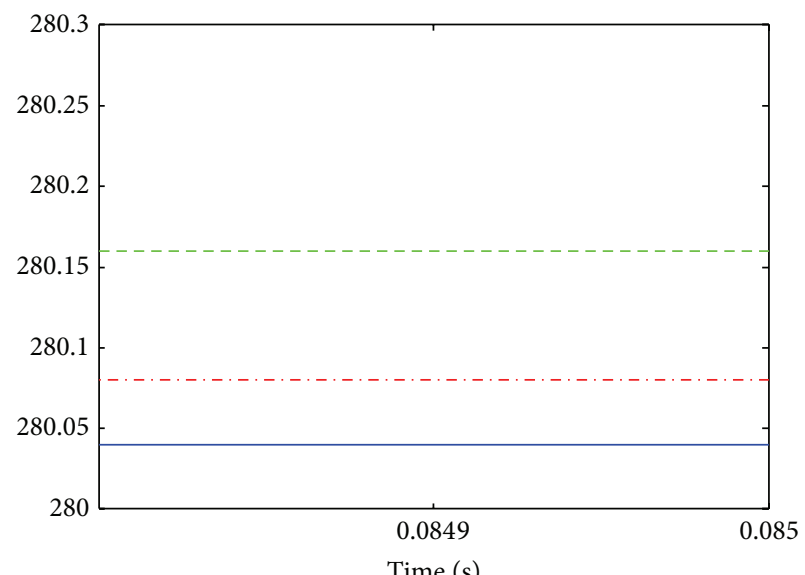

Time (s)

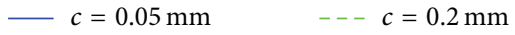

-. - $c=0.1 \mathrm{~mm}$

(b)

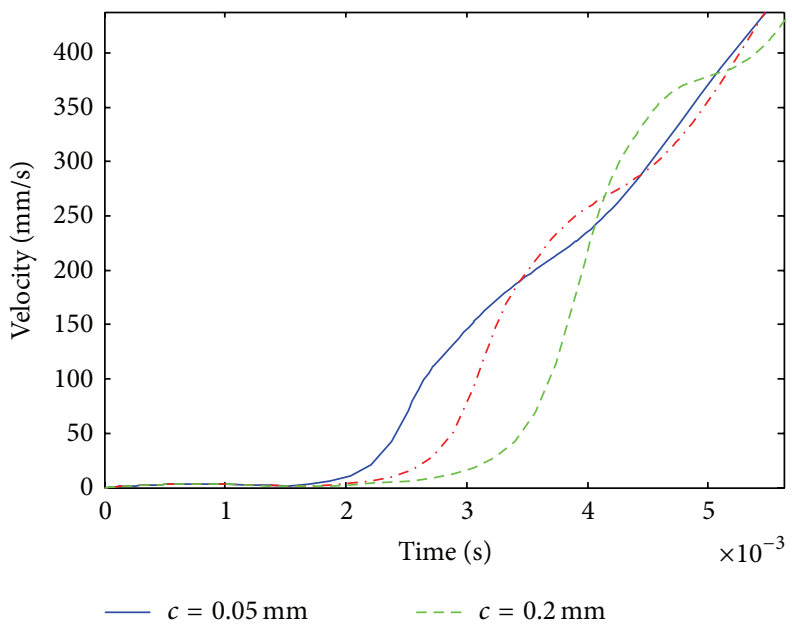

(d)

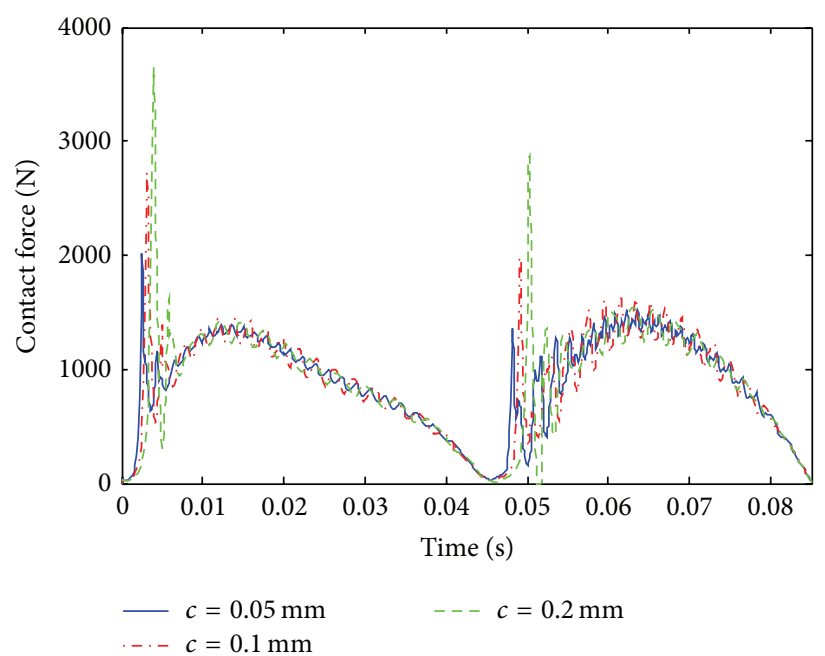

(f)

FIGURE 15: Responses for different clearance sizes: (a) displacement, (b) enlarged drawing of displacement, (c) velocity, (d) enlarged drawing of velocity, (e) acceleration, and (f) contact force. 


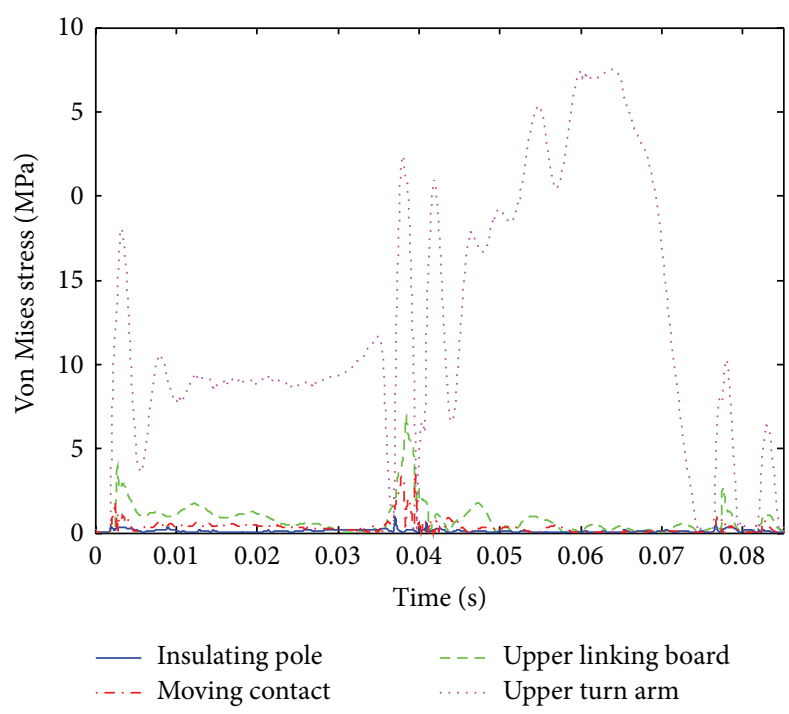

(a)

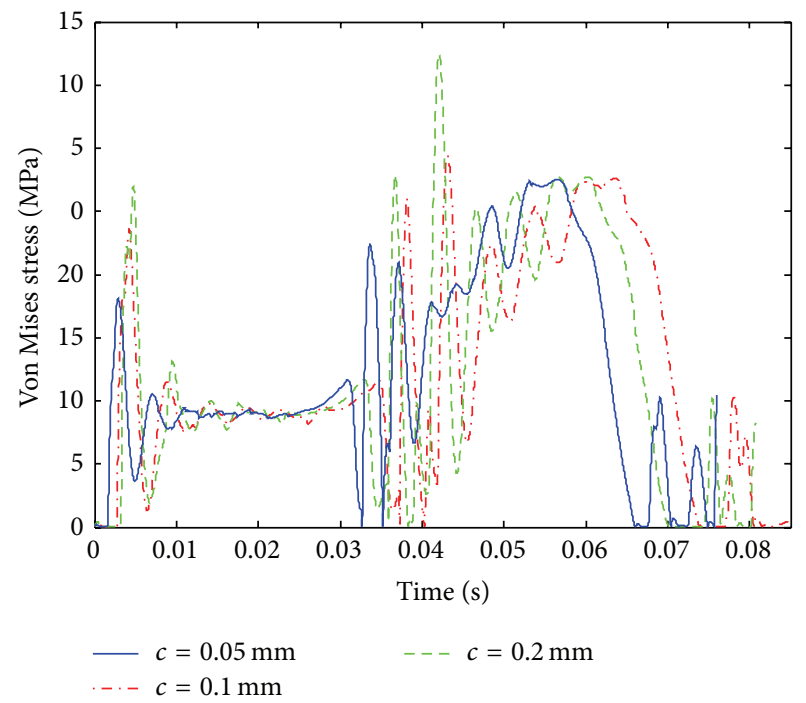

(b)

FIGURE 16: Dynamic stress for different clearance sizes: (a) Von Mises stress of the components and (b) Von Mises stress of upper turn arm.

generally consistent with those without clearance. The deviation value of the output stroke is $0.08 \mathrm{~mm}$. Compared with the rigid model without clearance, velocity and acceleration of the rigid-flexible coupling model without clearance produce large amplitude vibration in the starting stage of motion; the reason is that the high speed moving of transmission mechanism causes the excessive deformation of the flexible components, especially for the moving contact restricted by shifting pairs, which leads to clamping stagnation in the transmission motion. As can be seen from Figure 14(e), the existence of clearance can highly reduce the impact and vibration of the transmission mechanism. That is, the existence of clearance acts as the suspension for the rigidflexible coupling model.

Compared with the acceleration of rigid model with clearance, the maximum value of acceleration of rigid-flexible coupling model with clearance is reduced from $563.5 \mathrm{~m} / \mathrm{s}^{2}$ to $460.2 \mathrm{~m} / \mathrm{s}^{2}$. Therefore, for the case of the rigid-flexible coupling model, the maximum value of acceleration and impacts are dramatically reduced and the elastic components act as a suspension for the mechanism.

5.3. Influence of the Clearance Size. The effect of the clearance size on the dynamic responses of the rigid-flexible coupling model of the mechanism is investigated. During the dynamic simulation, the revolute joints $A$ and $J$ (Figure 2) are modeled as clearance joints. Three case studies are implemented for the different clearance sizes of $0.05 \mathrm{~mm}, 0.1 \mathrm{~mm}$, and $0.2 \mathrm{~mm}$. The displacement, vibration displacement, velocity, and acceleration of the moving contact for different clearance sizes are shown in Figure 15.

It is clear that the effects of the clearance sizes for revolute joint on the displacement and velocity of moving contact are slight, since the displacement and the velocity of moving contact without clearance are generally consistent with those of moving contact with different clearance sizes. However, with the increase in clearance size, the deviation value of the output stroke, the fluctuation frequency, and the hysteretic nature of velocity in time domain are more obvious. When the clearance size increases from $0.05 \mathrm{~mm}$ to $0.2 \mathrm{~mm}$, the corresponding deviation value of the output stroke increases from $0.04 \mathrm{~mm}$ to $0.17 \mathrm{~mm}$. Particularly, the time delay of velocity in the starting stage of motion increases from $0.0015 \mathrm{~s}$ to $0.0044 \mathrm{~s}$. Although the time is very short, it will lead to a kinematic error of about 7.8 percent for the transmission mechanism with characteristics of high speed and heavy haul, which causes a huge negative effect for transmission motion, even a serious Power Grid Accident.

The simulation results also verify that the effects of clearance size on contact force at the joint and acceleration of transmission mechanism are severer than those on displacement and velocity, especially for the high speed mechanism. Remarkably, the maximum value of acceleration increases from $345.5 \mathrm{~m} / \mathrm{s}^{2}$ to $612.2 \mathrm{~m} / \mathrm{s}^{2}$; the maximum value of contact force in joint $(J)$ increases from $2032.4 \mathrm{~N}$ to $3680.6 \mathrm{~N}$. The excessive contact force of the joints will greatly reduce the lifespan and dynamic performance of the mechanism.

As can be seen from Figure 16, during the simulation, the maximum dynamic stress of transmission mechanism occurs at the chamfer of upper turn arm. The reason is that it is constrained to the fixed axis rotation and has thin-walled structure in chamfer zone, which leads to bending moments and stress concentration. It can be seen that, with the increase in the clearance size, the maximum dynamic stress of upper turn arm increases from 13.63 MPa to 18.71 MPa. The simulation results indicate that the increase of the clearance size increases the level of dynamic stress of mechanism obviously.

In addition, the simulation results are compared to other studies form previous literature [23-25], in which the research results also revealed that clearance size played important roles in the dynamic performance of mechanical 


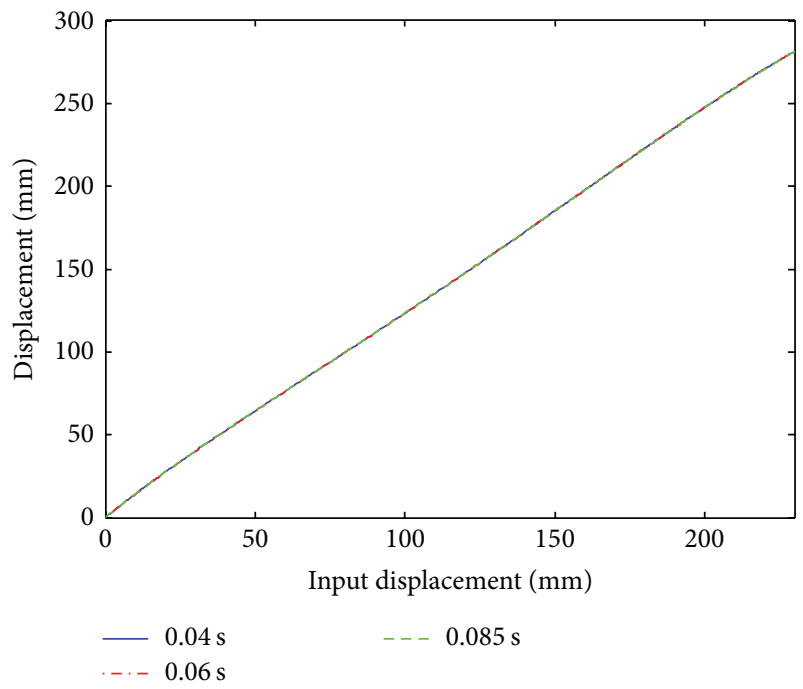

(a)

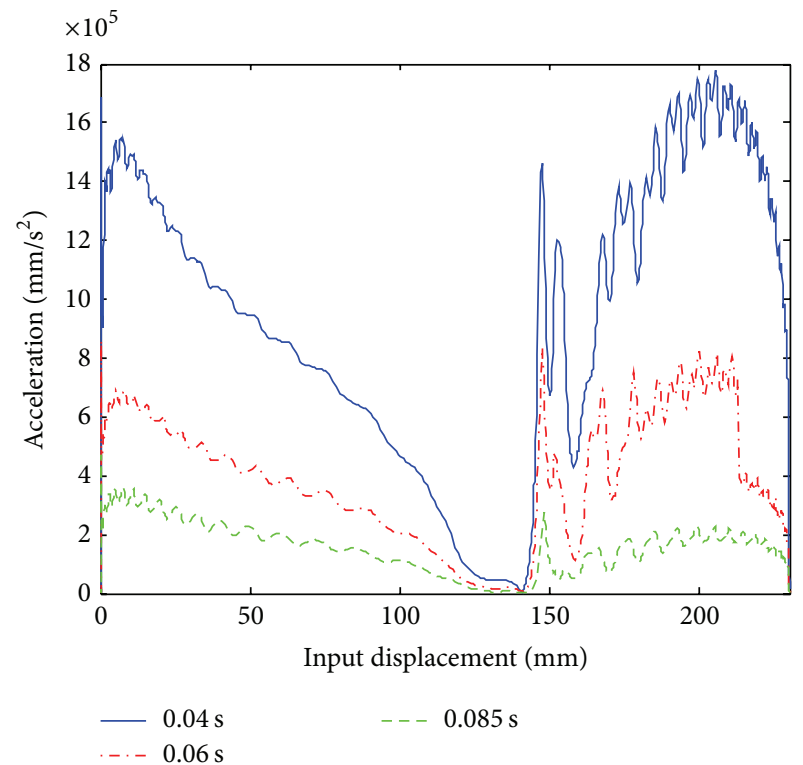

(c)

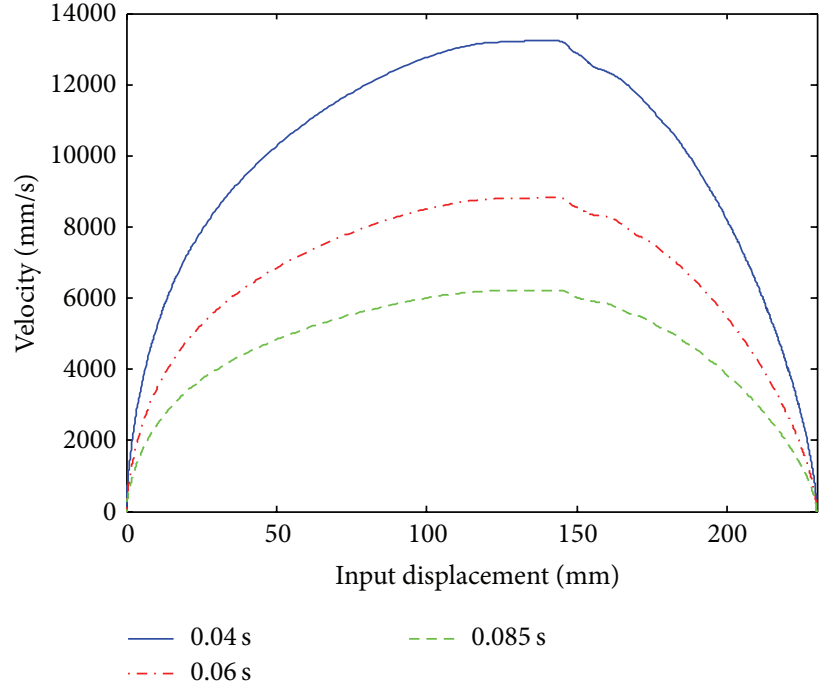

(b)

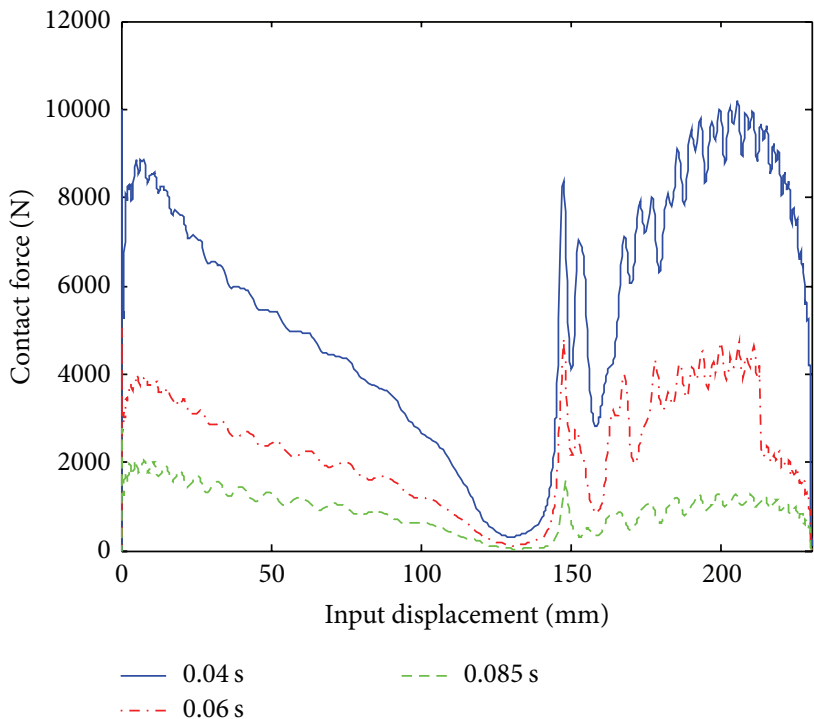

(d)

FIGURE 17: Responses for different input speeds: (a) displacement, (b) velocity, (c) acceleration, and (d) contact force.

system. It also represented that clearance leads to oscillations of mechanism, and higher size of clearance leads to larger amplitude of the acceleration of mechanism. So the simulation results are validated by other data published on the field on dynamics of mechanism with clearance joints.

5.4. Influence of the Input Speed. The influence of the input speed of driving link on the dynamic responses of the rigidflexible coupling transmission mechanism is investigated in this section. Again, in the simulation of transmission mechanism, the revolute joints $A$ and $J$ (Figure 2) are modeled as clearance joints. The clearance size of the revolute joints is set to $0.1 \mathrm{~mm}$.

When driving link's stroke is $230 \mathrm{~mm}$, the time duration of the simulation of transmission mechanism was $0.04 \mathrm{~s}$,
$0.06 \mathrm{~s}$, and $0.085 \mathrm{~s}$, respectively. That is, the input function of motion is, respectively, step5(time, $0,0,0.04,230$ ), step5(time, 0, 0, 0.06, 230), and step5(time, 0, 0, 0.085, 230). The displacement, velocity, acceleration, and contact force of the rigid-flexible coupling transmission mechanism with clearance are shown in Figure 17.

As can be seen from Figure 17, the different input speeds of driving link do not affect the displacement of moving contact in a significant way. In sharp contrast, the velocity, acceleration, and contact force of moving contact are strongly affected by input speed of driving link. With the increase in input speed of driving link, the maximum value of velocity of moving contact increases from $6.21 \mathrm{~m} / \mathrm{s}$ to $13.31 \mathrm{~m} / \mathrm{s}$, the value of contact force in clearance joint $(J)$ increases from $3820 \mathrm{~N}$ to $9754 \mathrm{~N}$, and that of acceleration increases from $460.2 \mathrm{~mm} / \mathrm{s}^{2}$ 

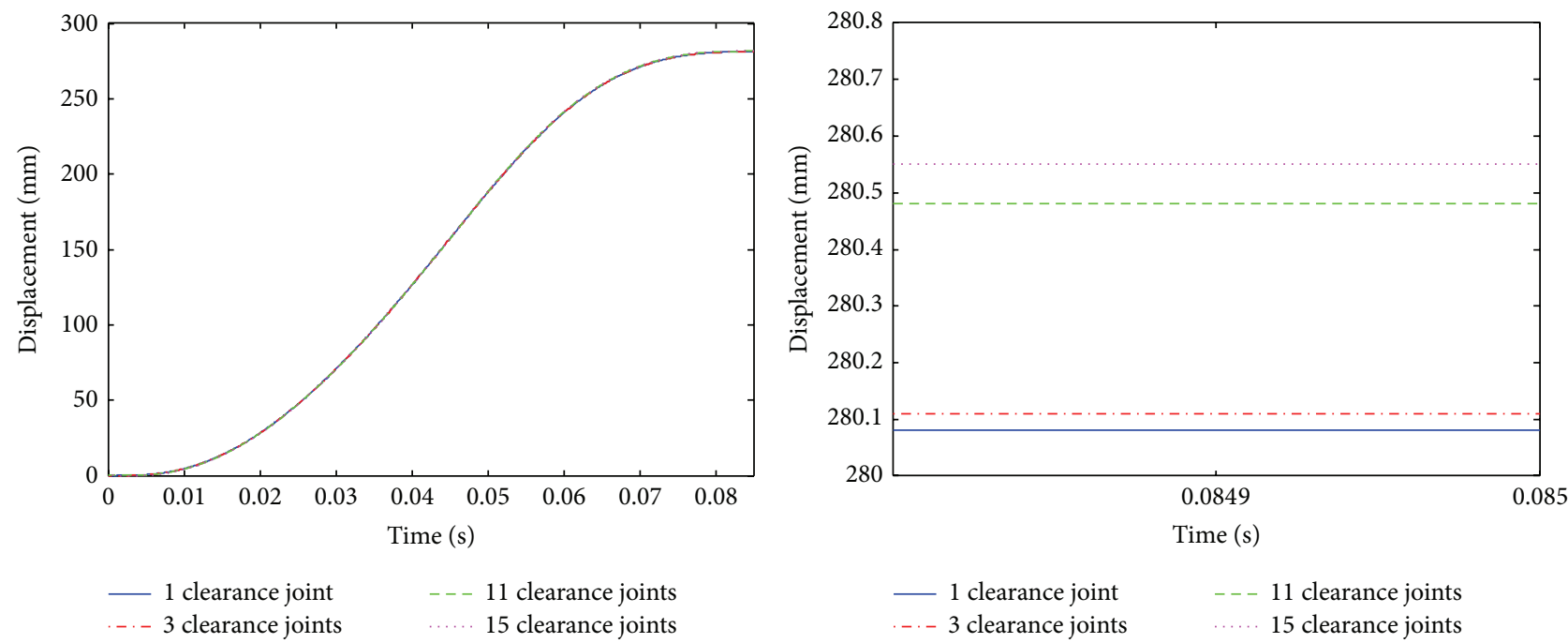

(a)

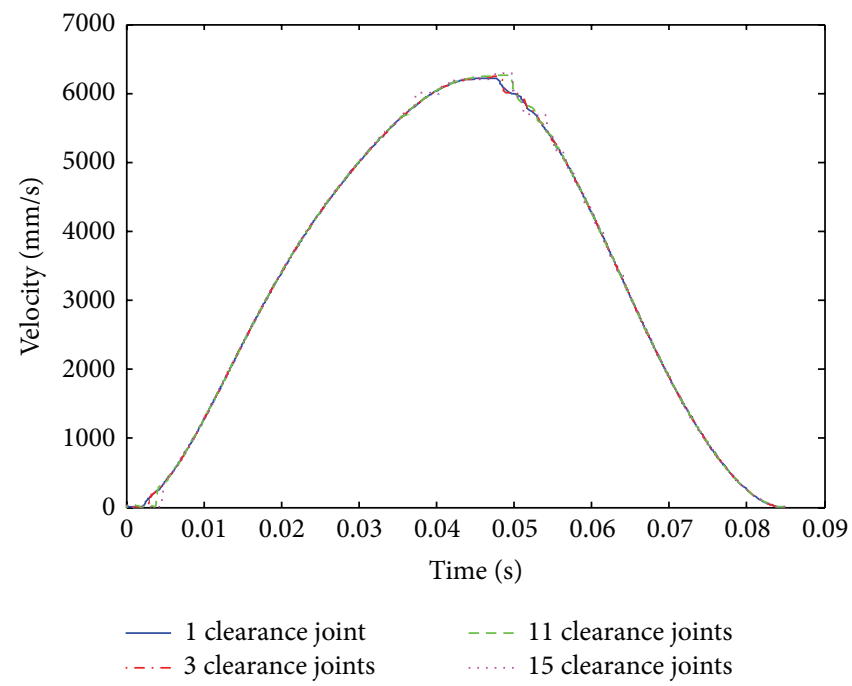

(c)

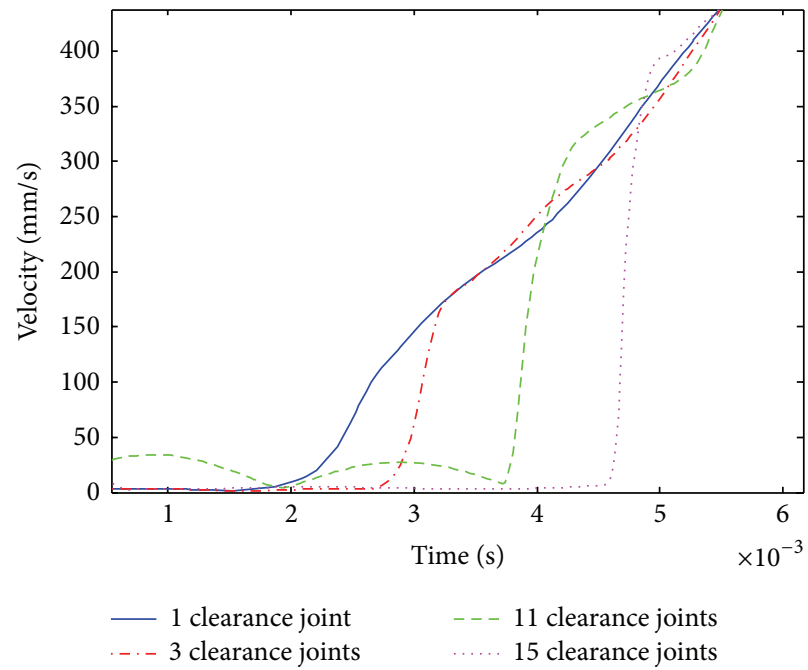

(d)

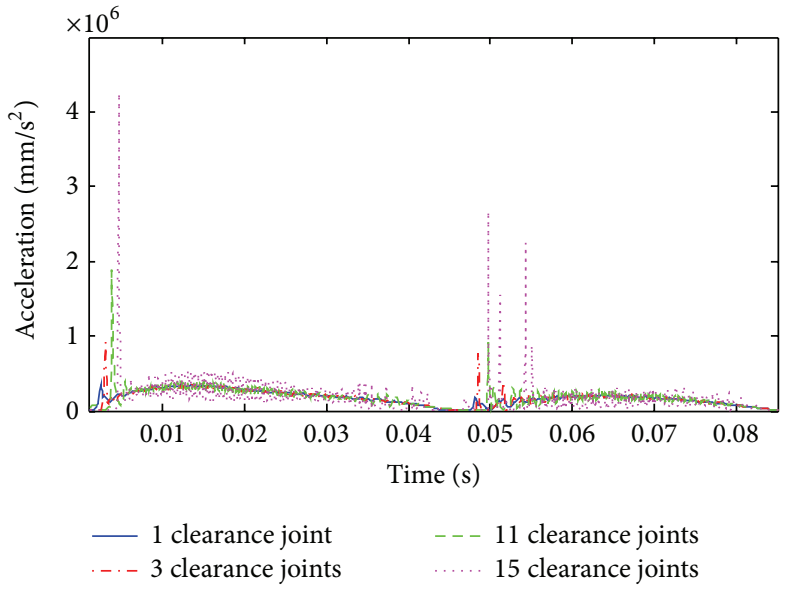

(e)

FIGURE 18: Responses for different number of clearance joints: (a) displacement, (b) enlarged drawing of displacement, (c) velocity, (d) enlarged drawing of velocity, and (e) acceleration. 
to $1625.6 \mathrm{~m} / \mathrm{s}^{2}$. It indicates the higher input speed, the higher acceleration, and contact force. Therefore, as the input speed increases, the effects of clearance on dynamic response of the mechanism are more obvious.

5.5. Influence of the Number of Clearance Joints. The simulation of transmission mechanism is performed with one, four, eleven, and fifteen clearance joints. In the simulation, the clearance size of revolute joint is set to be $0.1 \mathrm{~mm}$ and the simulation time duration is $0.085 \mathrm{~s}$; the displacement, velocity, and acceleration of the moving contact for different number of clearance joints are shown in Figure 18.

As can be seen from Figure 18, an increase in number of clearance joints causes the enhancement of the dynamic response of transmission mechanism. When the number of clearance joints increases from 1 to 15, the corresponding deviation value of the output stroke increases from $0.08 \mathrm{~mm}$ to $0.54 \mathrm{~mm}$, the time delay of velocity in the starting stage of motion increases from $0.0015 \mathrm{~s}$ to $0.0044 \mathrm{~s}$, and the maximum value of acceleration increases from $331.5 \mathrm{~m} / \mathrm{s}^{2}$ to $4260.6 \mathrm{~m} / \mathrm{s}^{2}$. With the increase of the number of clearance joints, the impact strength and vibration frequency will be stronger and higher. Therefore, the dynamic responses of transmission mechanism are affected tremendously by the number of clearance joints. As the number of clearance joints increases, the dynamic responses of the mechanism are more severe.

\section{Conclusion}

In this work, a planar rigid-flexible coupling model of the transmission mechanism of (UHV) with multiclearance joints is established using ADAMS software. The dynamic contact model in clearance joints is performed, in which the normal force is considered using nonlinear continuous contact force model and tangential force is considered using modified Coulomb's friction model. The reliability of the model is proved by means of comparing the results of experiments. Moreover, drawing into calculator simulation method for supplement because of the limitations on experiment, it has greater applicable scope.

The simulation results show that the dynamic response of the mechanism is influenced greatly by the clearance and components flexibility. Compared with the rigid model, in the case of flexible model, the maximum value of acceleration is highly reduced to about 1.5 times, and flexible components act as a suspension for the mechanism. Furthermore, the influences of clearance size, input speed, and number of clearance joints on the dynamic response of the mechanism are also investigated. It can be included that the increased clearance size, number of clearance joints, and input speed make the dynamic responses of mechanism worse, which leads to the destruction and failure of components and performs as more obvious motion lag and impact. In addition, this work provides a practical method to analyze the dynamics characteristics of transmission mechanism with clearance joints and can predict the effects of clearance on transmission mechanism preferably, which is the basis for precision analysis, optimization design of transmission mechanism, and reliability operation of breaker circuit.

\section{Conflict of Interests}

The authors declare that there is no conflict of interests regarding the publication of this paper.

\section{Acknowledgment}

The authors would like to express sincere gratitude to the Pinggao Technology for the financial and technological support given to this study through the project "High Voltage Circuit Breaker Hydraulic Operating Mechanism Characteristic Research" (Project no. 208239881).

\section{References}

[1] G. Song, J. Cui, and D. Yuan, "Operating analysis of high voltage circuit breaker in 1999-2003," Electrical Equipment, vol. 6, no. 2, pp. 6-13, 2005.

[2] A. Ziani and H. Moulai, "Hybrid model of electric arcs in high voltage circuit breakers," Electric Power Systems Research, vol. 92, pp. 37-42, 2012.

[3] W. Liu and B. Xu, "Characteristic analysis of high voltage circuit breaker with hydraulic operating mechanism," Journal of Mechanical Engineering, vol. 46, no. 10, pp. 148-155, 2010.

[4] F.-C. Chen and Y.-F. Tzeng, "On the dynamics of spring-type operating mechanism for $69 \mathrm{KV}$ SF6 gas insulated circuit breaker in open operation," Computers and Structures, vol. 80, no. 22, pp. 1715-1723, 2002.

[5] F.-C. Chen, "Dynamic response of spring-type operating mechanism for $69 \mathrm{kV}$ SF6 gas insulated circuit breaker," Mechanism and Machine Theory, vol. 38, no. 2, pp. 119-134, 2003.

[6] T.-M. Lyu and J.-P. Tao, "Calculation and improvement of spring operating mine-used device for vacuum circuit breaker," Coal Mine Machinery, vol. 35, no. 9, pp. 34-36, 2012.

[7] P. Flores, "A parametric study on the dynamic response of planar multibody systems with multiple clearance joints," Nonlinear Dynamics, vol. 61, no. 4, pp. 633-653, 2010.

[8] S. Erkaya and I. Uzmay, "A neural-genetic (NN-GA) approach for optimising mechanisms having joints with clearance," Multibody System Dynamics, vol. 20, no. 1, pp. 69-83, 2008.

[9] Q. Tian, Y. Zhang, L. Chen, and P. Flores, "Dynamics of spatial flexible multibody systems with clearance and lubricated spherical joints," Computers and Structures, vol. 87, no. 13-14, pp. 913-929, 2009.

[10] E. Zheng and X. Zhou, "Modeling and simulation of flexible slider-crank mechanism with clearance for a closed high speed press system," Mechanism and Machine Theory, vol. 74, pp. 1030, 2014.

[11] Z.-F. Bai, Y. Zhao, and H. Tian, "Dynamics simulation of deployment for solar panels with hinge clearance," Journal of Harbin Institute of Technology, vol. 41, no. 3, pp. 11-14, 2009.

[12] P. Flores, J. Ambrósio, and J. P. Claro, "Dynamic analysis for planar multibody mechanical systems with lubricated joints," Multibody System Dynamics, vol. 12, no. 1, pp. 47-74, 2004.

[13] P. Flores, J. Ambrósio, J. C. P. Claro, and H. M. Lankarani, "Influence of the contact-impact force model on the dynamic response of multi-body systems," Proceedings of the Institution of Mechanical Engineers, Part K, vol. 220, no. 1, pp. 21-34, 2006.

[14] I. Khemili and L. Romdhane, "Dynamic analysis of a flexible slider-crank mechanism with clearance," European Journal of Mechanics-A/Solids, vol. 27, no. 5, pp. 882-898, 2008. 
[15] O. Muvengei, J. Kihiu, and B. Ikua, "Numerical study of parametric effects on the dynamic response of planar multi-body systems with differently located frictionless revolute clearance joints," Mechanism and Machine Theory, vol. 53, pp. 30-49, 2012.

[16] S. M. Megahed and A. F. Haroun, "Analysis of the dynamic behavioral performance of mechanical systems with multiclearance joints," Journal of Computational and Nonlinear Dynamics, vol. 7, no. 1, Article ID 011002, 11 pages, 2012.

[17] O. A. Bauchau and J. Rodriguez, "Modeling of joint clearances and joint flexibility effects in multibody systems dynamics," International Journal of Solids and Structures, no. 39, pp. 41-63, 2002.

[18] Q. Tian, Y. Zhang, L. Chen, and J. Yang, "Simulation of planar flexible multibody systems with clearance and lubricated revolute joints," Nonlinear Dynamics, vol. 60, no. 4, pp. 489-511, 2010.

[19] Q. Tian, C. Liu, M. MacHado, and P. Flores, "A new model for dry and lubricated cylindrical joints with clearance in spatial flexible multibody systems," Nonlinear Dynamics, vol. 64, no. 12, pp. 25-47, 2011.

[20] A. L. Schwab, J. P. Meijaard, and P. Meijers, "A comparison of revolute joint clearance models in the dynamic analysis of rigid and elastic mechanical systems," Mechanism and Machine Theory, vol. 37, no. 9, pp. 895-913, 2002.

[21] Z. F. Bai and Y. Zhao, "A hybrid contact force model of revolute joint with clearance for planar mechanical systems," International Journal of Non-Linear Mechanics, vol. 48, pp. 1536, 2013.

[22] D.-Y. Yu and Y.-J. Qian, "Parameter-settings for the dynamic simulation based on ADAMS," Computer Simulation, no. 9, pp. 103-107, 2006.

[23] S. Erkaya, "Investigation of joint clearance effects on welding robot manipulators," Robotics and Computer-Integrated Manufacturing, vol. 28, no. 4, pp. 449-457, 2012.

[24] K.-L. Ting, J. Zhu, and D. Watkins, "The effects of joint clearance on position and orientation deviation of linkages and manipulators," Mechanism and Machine Theory, vol. 35, no. 3, pp. 391-401, 2000.

[25] A. Kote, K. Balaji, B. S. Nataraju, and V. C. Aralimatti, "Effect of solar array deployment on spacecraft attitude," Journal of Spacecraft Technology, vol. 17, no. 2, pp. 1-8, 2007. 

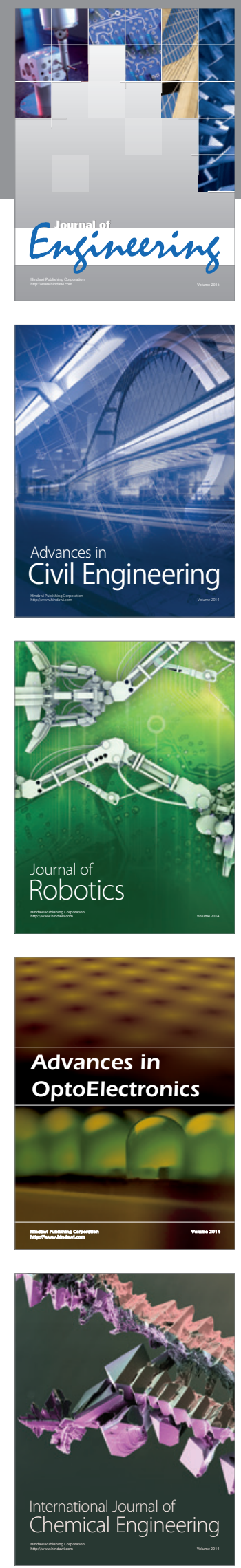

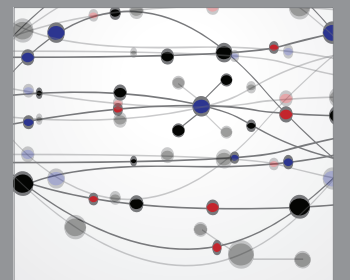

The Scientific World Journal
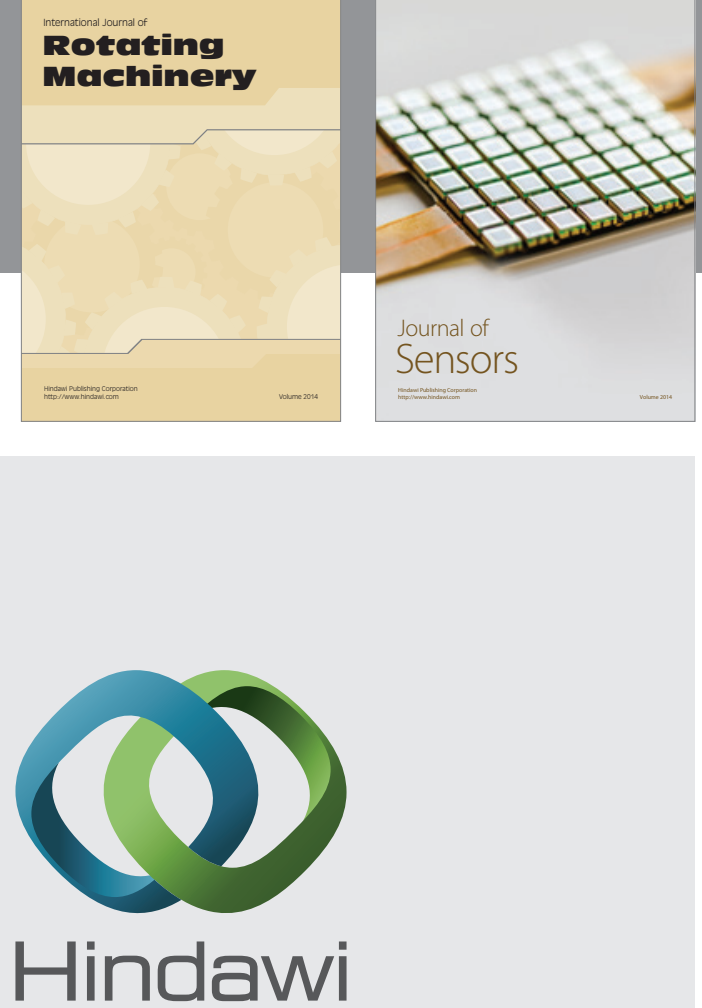

Submit your manuscripts at http://www.hindawi.com
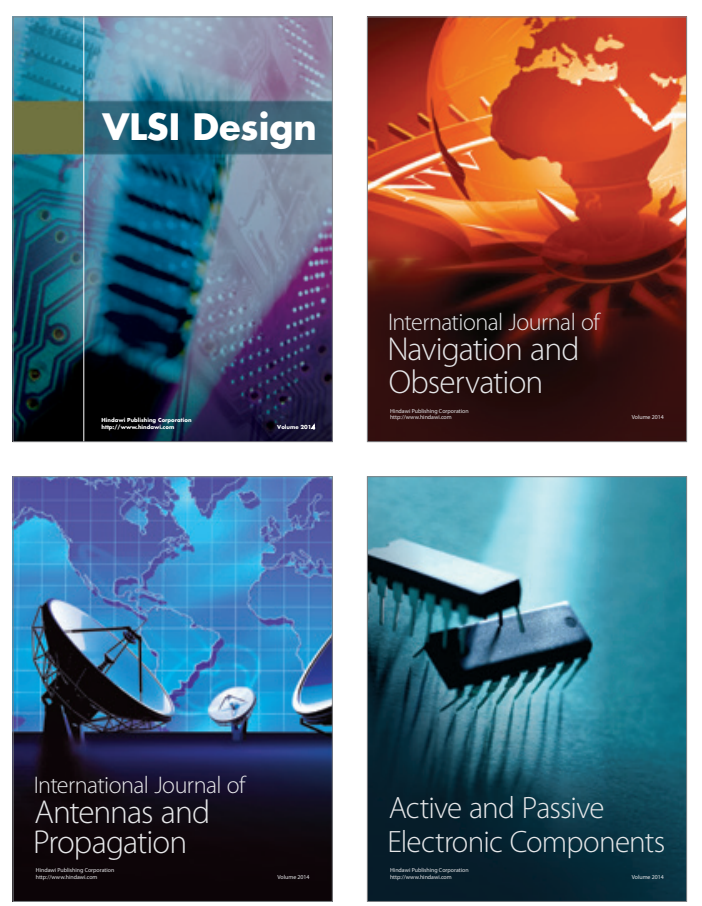
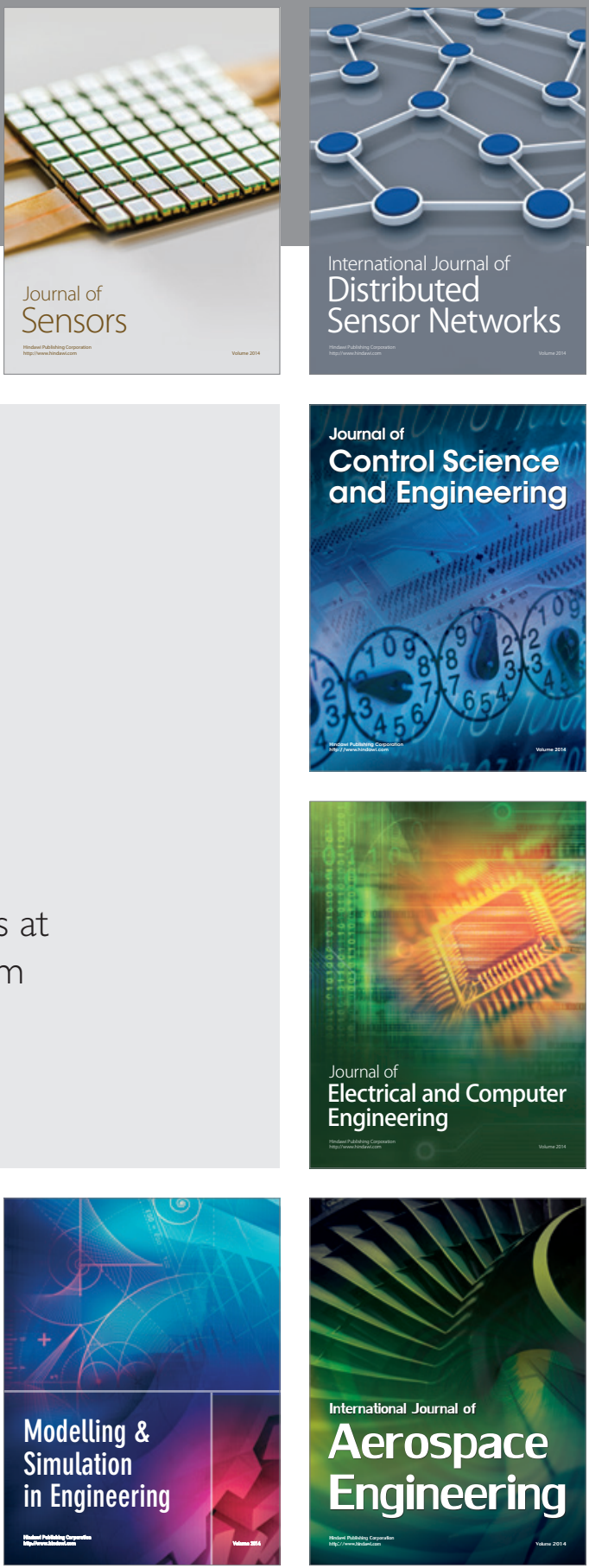

Journal of

Control Science

and Engineering
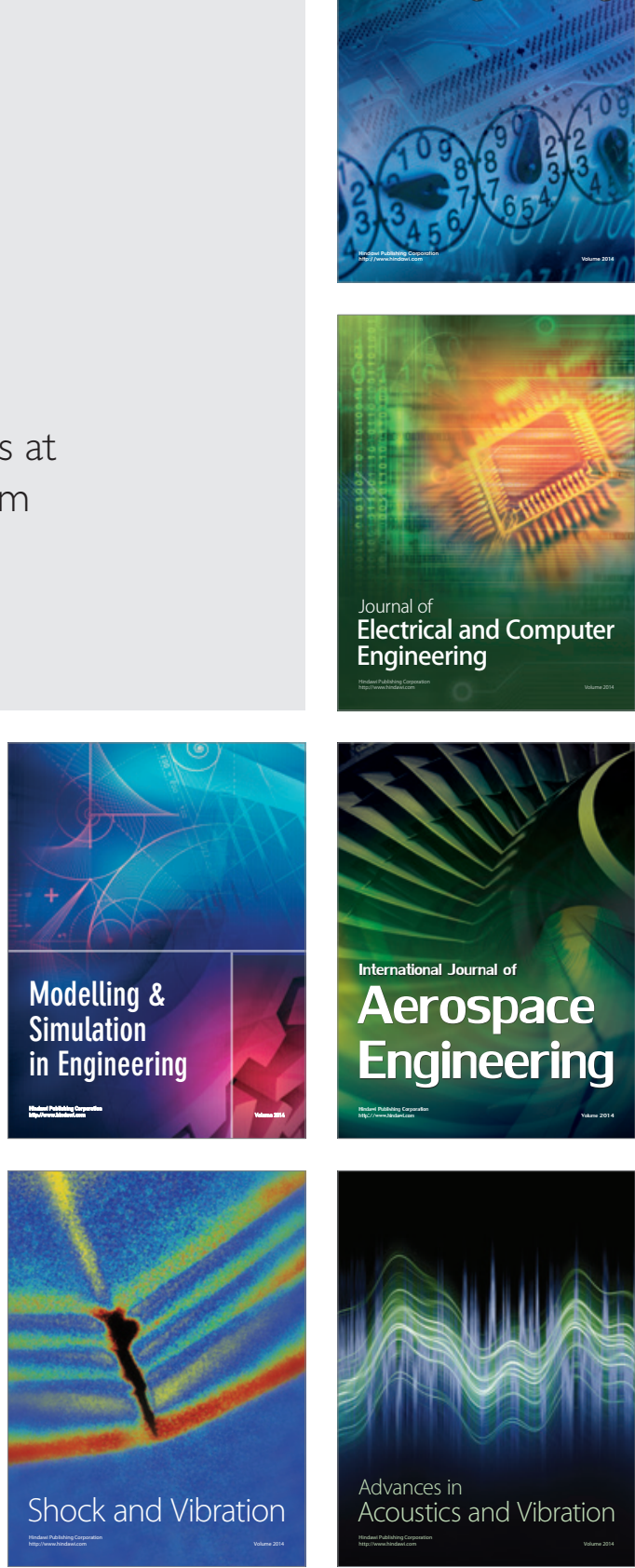